\title{
The Controls of Pore-Throat Structure on Fluid Performance in Tight Clastic Rock Reservoir: A Case from the Upper Triassic of Chang 7 Member, Ordos Basin, China
}

\author{
Yunlong Zhang $\mathbb{D}^{1,2}$ Zhidong Bao $\mathbb{D}^{2},{ }^{2}$ Fei Yang, ${ }^{2}$ Shuwei Mao, ${ }^{2}$ Jian Song, ${ }^{2}$ and Li Jiang ${ }^{3}$ \\ ${ }^{1}$ Division of Geology and Mineral Resources, CNNC Beijing Research Institute of Uranium Geology, No. 10 Anwai Xiaoguandongli, \\ Chaoyang, Beijing 100029, China \\ ${ }^{2}$ College of Geosciences, China University of Petroleum-Beijing, No. 18 Fuxue Road, Changping, Beijing 102249, China \\ ${ }^{3}$ Research Center for Strategy of Global Mineral Resources, Institute of Mineral Resources, Chinese Academy of Geological Sciences, \\ Beijing 100037, China
}

Correspondence should be addressed to Yunlong Zhang; ylong.zhang@yahoo.com and Zhidong Bao; baozhd@cup.edu.cn

Received 14 April 2017; Revised 18 August 2017; Accepted 22 October 2017; Published 16 January 2018

Academic Editor: Micol Todesco

Copyright (c) 2018 Yunlong Zhang et al. This is an open access article distributed under the Creative Commons Attribution License, which permits unrestricted use, distribution, and reproduction in any medium, provided the original work is properly cited.

\begin{abstract}
The characteristics of porosity and permeability in tight clastic rock reservoir have significant difference from those in conventional reservoir. The increased exploitation of tight gas and oil requests further understanding of fluid performance in the nanoscale pore-throat network of the tight reservoir. Typical tight sandstone and siltstone samples from Ordos Basin were investigated, and rate-controlled mercury injection capillary pressure (RMICP) and nuclear magnetic resonance (NMR) were employed in this paper, combined with helium porosity and air permeability data, to analyze the impact of pore-throat structure on the storage and seepage capacity of these tight oil reservoirs, revealing the control factors of economic petroleum production. The researches indicate that, in the tight clastic rock reservoir, largest throat is the key control on the permeability and potentially dominates the movable water saturation in the reservoir. The storage capacity of the reservoir consists of effective throat and pore space. Although it has a relatively steady and significant proportion that resulted from the throats, its variation is still dominated by the effective pores. A combination parameter $(\varepsilon)$ that was established to be as an integrated characteristic of pore-throat structure shows effectively prediction of physical capability for hydrocarbon resource of the tight clastic rock reservoir.
\end{abstract}

\section{Introduction}

Hydraulic properties of rock formations are critical to evaluate the economic viability of petroleum, gas, and geothermal and groundwater reservoirs $[1,2]$. To investigate the fluid flow mechanism in porous materials, Henry Darcy did massive experiments and developed his famous correlation to describe the dynamics of fluid flow in porous media, namely, for Darcy Law. However, the further research of percolation in tight reservoir, particularly in nanoporous reservoir, shows that hydraulic characteristics are more complicated and multicontrolled, which is beyond Darcy Low [3-6]. The deviation from the linearity of Darcy's equation was observed at high flow rate [7], and this is called non-Darcy flow [8]. In tight reservoir, capillary flow, which was proposed by Washburn [9], as a kind of non-Darcy flow, dominated the seepage mechanism in the reservoir sophisticatedly and received more and more attention in researches of reservoir quality and petroleum and gas recovery [10-15].

The non-Darcy coefficient, as called by Saboorian-Jooybari and Pourafshary [4], in the equation that is used to describe the non-Darcy flow was hard to defined. Therefore, the behavior of fluid in tight reservoir still awaits to be revealed. To investigate the fluid performance in tight clastic rock reservoir, some experiments and studies returned back to the essential issues, including the pore-throat structure and physical interaction of fluid-pore-wall in the tight reservoir $[6,10,13,15-24]$. However, the pore-throat structures are various significantly in tight clastic rock reservoir and the fluid flow inside needs to be particularly concerned [25-29]. 
Lots of techniques have been used for studying the porethroat structure of the tight reservoir, including scanning electron microscopy (SEM), X-ray computer tomography (CT), and mercury injection capillary pressure (MICP). MICP, testing the capillary pressure and mercury saturation, can obtain pore-size distribution by calculation of Washburn [9] equation and more detailed parameters of the pore-throat network, such as threshold pressure as defined by Katz and Thompson [30] and displacement pressure as defined by Schowalter [31]. This technique was used by lots of scholars to research the pore-throat structures and try to relate these characteristics to simple and easy obtained parameters, such as permeability and porosity, and further to estimate the reservoir quality for economic fluid pay [32-35]. With the increase of unconventional hydrocarbon resource exploitation in recent years, some applications have to be conducted in the tight fine-grained sandstone, siltstone, carbonate rocks, and shale $[3,15,28,36-38]$. By controlling the mercury injection rate to be constant approximately and in a very low magnitude, the capillary-pressure curves can be obtained by partitioning the total capillary-pressure curve (normal capillary-pressure curve) into two subcurves, the subison capillary-pressure curve, which details the distribution of pore bodies, and the rison capillary-pressure curve, which details the distribution of throats bodies [39]. This technique is named the rate-control mercury injection capillary pressure (RMICP).

Under the clarified condition, nuclear magnetic resonance (NMR) leads to a feasible analysis of fluid saturation, which could be linked to the pore-throat structures that are tested by RMICP. NMR, as a technique of detecting the presence of hydrogen nuclei and obtaining more information about the fluid in the reservoir by recording the transverse relaxation time $\left(T_{2}\right)$, was used to analyze the lithologyindependent porosity, fluid typing, and pore-throat system [40-46]. The laboratory test of NMR measures the rate at which the precession of hydrogen nuclei in the pore fluid gradually dephases in the presence of an inhomogeneous magnetic field, which could be used for estimating the saturation of hydrogen phase in the reservoir.

The samples from Chang 7 Member of Upper Triassic in Ordos Basin, China, is typically tight clastic rock reservoir, including fine-grained sandstone and siltstone [47, 48]. The exploitation of unconventional oil and gas in these tight reservoir appeals to more detailed researches of the controls on the storage and seepage capacity of the reservoir, which has been linked to the pore-throat structure essentially. Based on the conventional helium porosity and air permeability data, here we employed RMICP and NMR as a combination to address the following issues:

What dominated the porosity and permeability of tight clastic rock reservoir?

How does the pore-throat structure impact on reservoir storage capacity?

What controls the valid porosity for hydrocarbon, particularly for petroleum, in tight clastic rock reservoir?

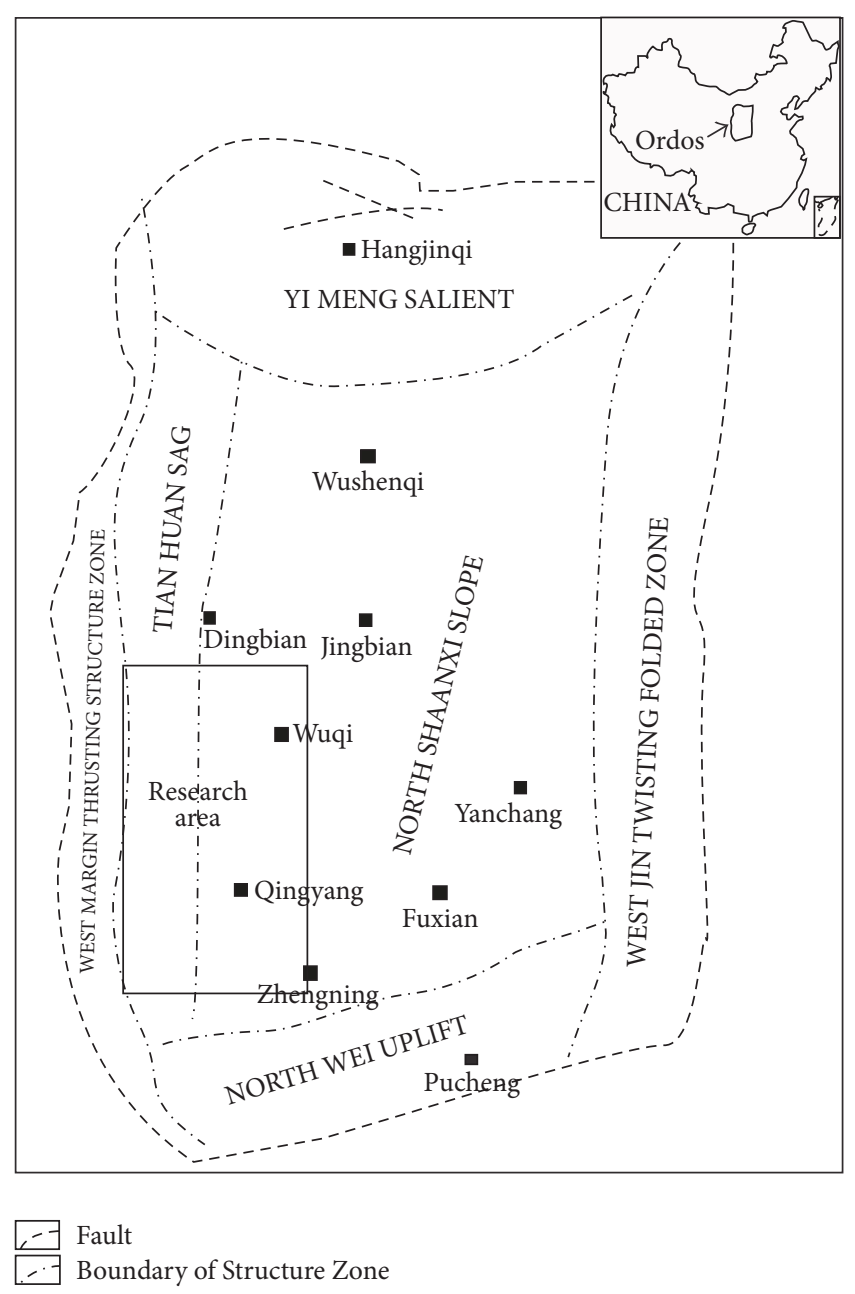

Figure 1: The location of research area and the Ordos Basin.

How does the pore-throat structure affect the irresistible water saturation in the tight reservoir?

\section{Geological Setting}

The Ordos Basin, located in central China (Figure 1), formed as an intraplate depression on the northwest China craton during the Mesozoic and Cenozoic. The basin is formed on top of Paleoproterozoic crystalline basement $[49,50]$ and now comprises six tectonic belts [51]. The Ordos Basin first formed in the early Triassic due to uplift in the east and subsidence in the west. Four transient inversion events have been identified between the Triassic and the present day [52]. The continuous subsidence was the overall characteristic of the basin up to the mid Cretaceous. The present burial depth of Chang 7 in the area of interest (Longdong area) is about 2,500 to $3,000 \mathrm{~m}$. The Longdong area is located in the southwest part of the Ordos Basin (Figure 1).

The Ordos Basin started as a lacustrine basin at the onset of the Upper Triassic Yanchang Stage. The oldest unit, Chang 10, was a lake-marginal fluvial deposit. Evolving through Chang 9 and Chang 8, Chang 7, the unit of interest, occurred in a relatively deep lacustrine setting due to an 
increase in base level (Figure 2). Chang 7 was deposited in a lacustrine delta front environment in research area. From Chang 7 to Chang 1, the youngest unit, sedimentation occurred in progressively shallower lake waters. Maximum flooding therefore occurred in the Chang 7 period; this resulted in widely distributed, organic-rich, source rocks in the Ordos Basin [54]. The Chang 7 Member is thus the dominant source rock that has charged a number of Yanchang Formation reservoirs $[55,56]$. Chang 7 is dominated by thickbedded, mudstone-dominated, organic-enriched dark shale in the lower sections [57], with tight sandstone and siltstone, the focus of this research, interbedded with shale in the upper sections.

\section{Methods}

The slow constant-rate mercury intrusion reduced the changes of capillary pressure caused by fluid velocity to negligible. Therefore, the shape of fluid front surface changes with the variation of pore geometry, which is determined and recorded by capillary pressure. In the beginning of the injection, the pressure increases steadily until the point it drops down rapidly (this process is called rison). The dropdown point stands for the maximum throat that has been broken in. Then the pores and suborder throats are filled up; this process is, named subison, continued until the pressure returns back to the first pressure drop-down point, and then it increases again to the next process of rison and subison. This technique resolves the space of the reservoir into pore bodies (subisons) and throats (risons); each of them is characterized by entry pressure and mercury volume curve [58].

The relationship between pressure $\left(P_{c}\right)$ and pore-throat radius $(R)$ has been given by the Young-Laplace law for the particular case of cylindrical pores as the Washburn equation $[59,60]$ :

$$
R=\frac{2 \gamma_{\mathrm{Hg}} \cos \left(\theta_{\mathrm{Hg}}\right)}{P_{c}} .
$$

This equation dictates that, with increasing pressure, the mercury will intrude into progressively narrower pores for constant values of contact angle $\left(\theta_{\mathrm{Hg}}\right)$ of mercury with the porous material intruding and mercury surface tension $\left(\gamma_{\mathrm{Hg}}\right)$ [60].

Using this function to the RMICP result, pore and throat radii could be calculated separately, and further the ratio of pore/throat in volume can be obtained.

In this paper, ASPE-730 RMICP device has been employed; the operation followed the standard Q/SY DQ15312012 of Daqing Oilfield, CNPC, China [61]. Mercury injection rate was a constant value of $5 \times 10^{-5} \mathrm{ml} / \mathrm{min}$, and maximum intrusion pressure was $900 \mathrm{psi}(6.21 \mathrm{MPa})$ in order to keep the injection rate quasistatic. This corresponds to a pore-throat radius of $0.12 \mu \mathrm{m}$.

Nuclear magnetic resonance technique records the net magnetization (signal amplitude and relaxation time decay) of a hydrogen atom or proton ${ }^{1} \mathrm{H}$ (abundant in water and hydrocarbon) in the presence of an external magnetic field [11]. The magnetization of the protons in the fluid relaxes exponentially with the constant of proportionality being the transverse relaxation time $\left(T_{2}\right)$. The transverse relaxation time due to surface relaxation is a function of surface relaxivity (constant) and surface area to volume ratio of the pore, which is derived from the equivalent volume of fluid $[62,63]$.

Some effects may affect the NMR signal that we need to know, such as pore coupling [41] or surface relaxivity variation with mineralogy [64] and the heterogeneity of the magnetic field. These may affect the interpretation of NMR signals [46].

The samples for NMR were dried and vacuumed completely and then immerged in the $8 \% \mathrm{KCl}$ solution to reach saturation. NMR analysis was operated by Research Institute of Petroleum Exploration and Development, CNPC, using MAGNET2000 device with a resonance frequency of $2.38 \mathrm{MHz}$ and a magnetic field strength of $1200 \mathrm{G} . T_{2}$ spectrums were recorded at water saturation and centrifuged condition separately. The samples were centrifuged at a pressure of $200 \mathrm{psi}(1.38 \mathrm{MPa})$ to reach irreducible water state.

The experiment was operated in Research Institute of Petroleum Exploration and Development, CNPC, and the data was provided by PCOC, including helium porosity and air permeability data.

\section{Result}

4.1. Porosity and Permeability. The measured porosity and permeability in these samples are shown in Table 1 . The core analysis helium porosity varies from $6.32 \%$ to $14.59 \%$ with an average $10.82 \%$. The air permeability varies from 0.0068 to $0.139 \times 10^{-3} \mu \mathrm{m}^{2}$ with an average of $0.0377 \times 10^{-3} \mu \mathrm{m}^{2}$. The cross-plot shows that the permeability and porosity have a weak correlation; even the low porosity samples have higher permeability than that in those high porosity samples. The samples that have low porosity (less than $8 \%$ ) have a relatively high permeability (average $0.076 \times 10^{-3} \mu \mathrm{m}^{2}$ ); on the contrary, the samples that have high porosity (more than $14 \%$ ) show low permeability values (average $0.014 \times 10^{-3} \mu \mathrm{m}^{2}$ ) (Figure 3 ). This is opposite to the common conclusion gained from the conventional reservoir.

4.2. Rate-Controlled Mercury Injection Capillary Pressure (RMICP). The processes of mercury injection capillarypressure test record the volume of injected mercury and the corresponding capillary-pressure. Combining the porosity and bulk volume of the sample, the mercury saturation can be calculated from the injected mercury volume. With the RMICP technique, throat and pore capillary pressure and mercury saturation can be recorded separately. As an example, RMICP curve was illustrated in Figure 4; their detailed characteristic parameters are shown in Table 1. Following the processes of RMICP, constant injection rate increased the pressures in the beginning persistently; the first pressure-drop point presents the maximum size of throat that has been broken in. This entry pressure, being indicative of the largest throat radius [65], was defined as threshold pressure in this paper. The threshold pressure of these tight reservoirs ranges from 159 to $292 \mathrm{psi}$ (1.1 to $2.01 \mathrm{MPa}$ ), with 

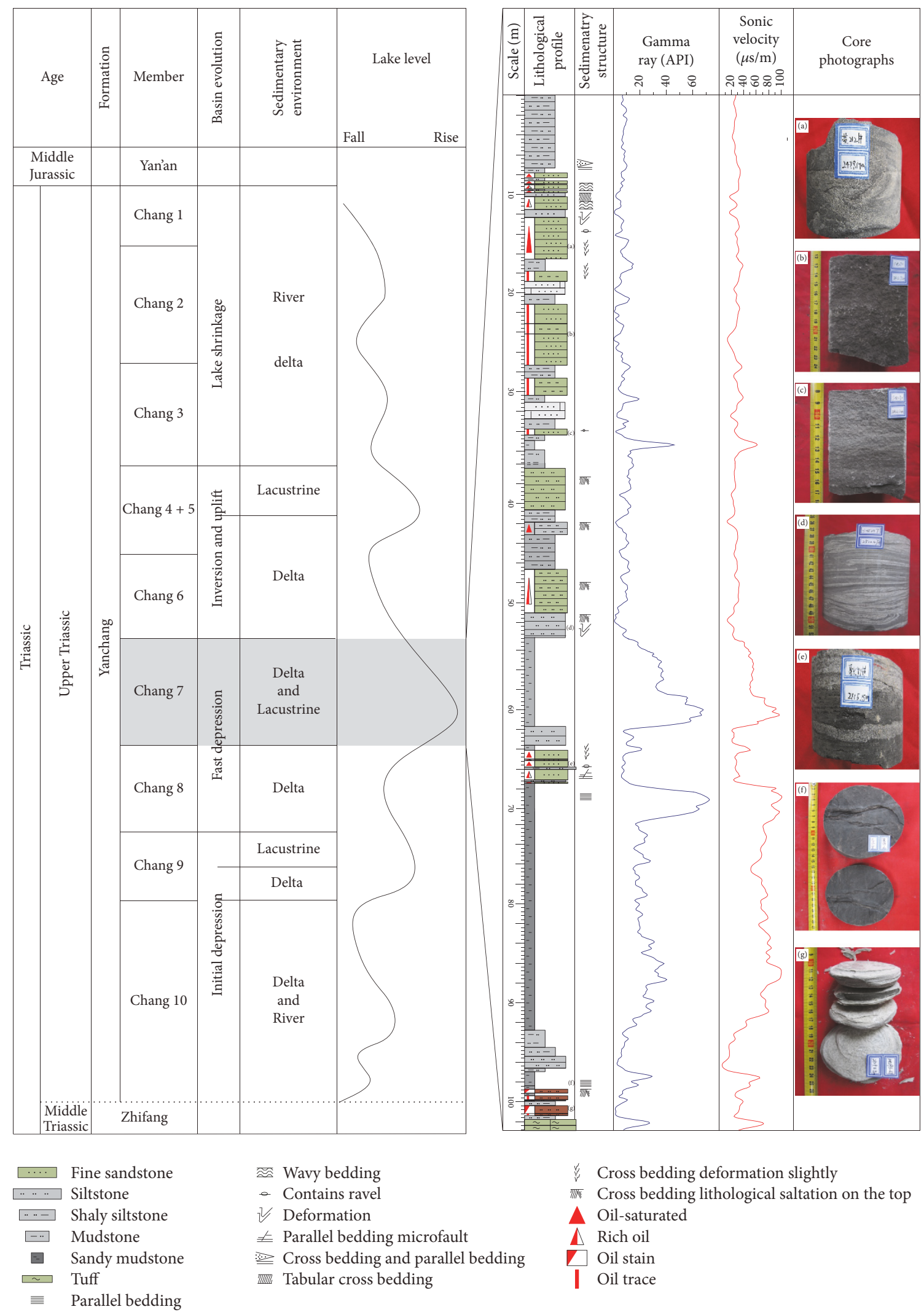

Cross bedding deformation slightly

IIN Cross bedding lithological saltation on the top

$\Delta$ Oil-saturated

$\triangle$ Rich oil

Oil stain

I Oil trace

FIGURE 2: Stratigraphy description of the Upper Triassic Yanchang Formation with basin evolution, sedimentary environment and lake level changing curve (modified after [53]), and lithofacies, sedimentary structure, wireline log, and core photographs of the Chang 7 Member. 


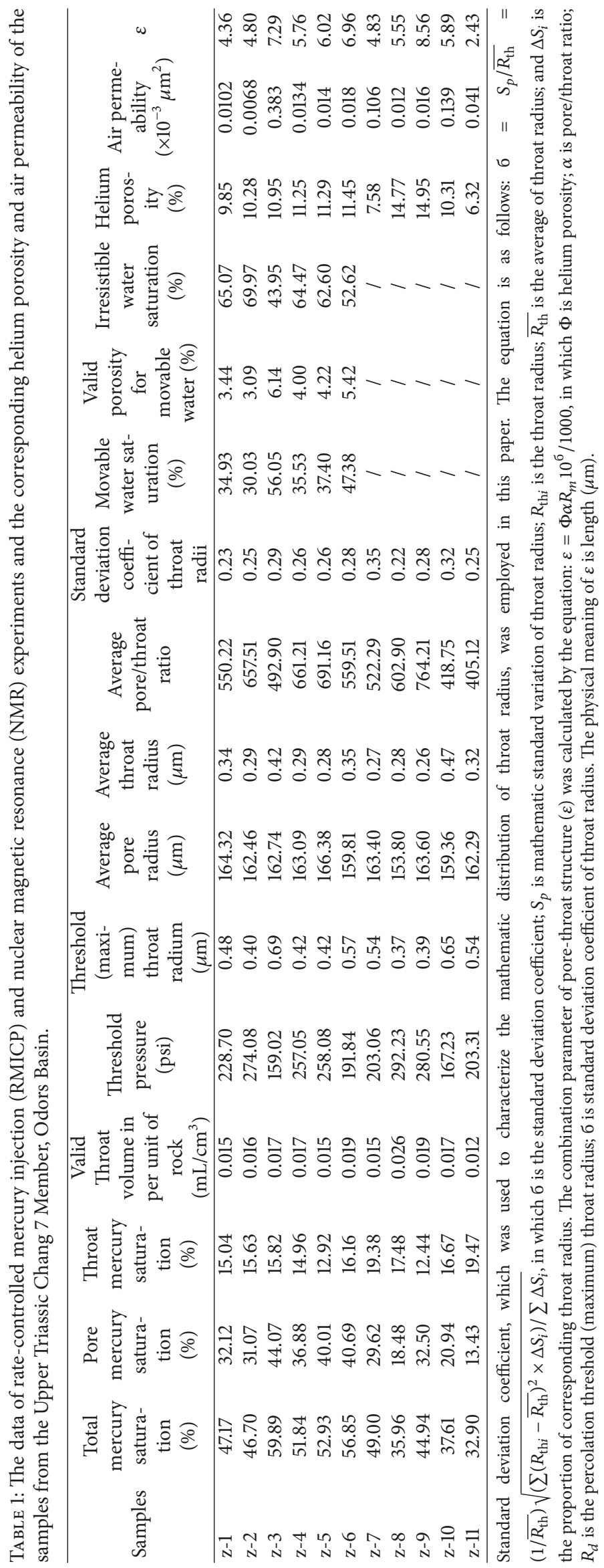




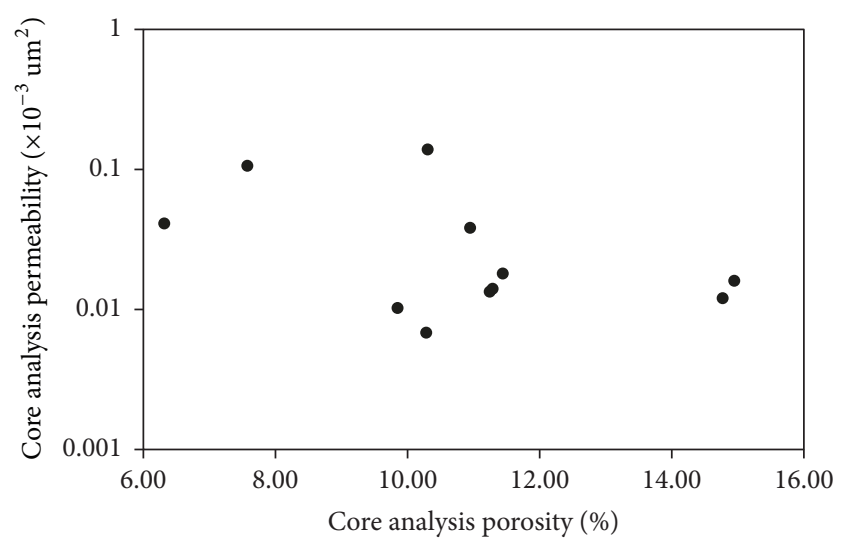

FIgure 3: The correlation of porosity and permeability of the samples from Upper Triassic Chang 7 Member, Odors Basin.

an average of $228.7 \mathrm{psi}(1.58 \mathrm{MPa})$ (Table 1 and Figure 4). Calculated from the threshold pressure, the maximum throat radius in these samples ranges from 0.37 to $0.69 \mu \mathrm{m}$; the average is $0.5 \mu \mathrm{m}$. Finally, the mercury saturation reached the peak which is different between samples. The finally mercury saturation of the samples varies from about 33 to $60 \%$ with an average of about $47 \%$ (Table 1 and Figure 4 ). Separately, the pore mercury saturation varies from about 13 to $44 \%$ with an average of about $31 \%$; and the throat mercury saturation varies from about 12 to $19 \%$ with an average of $16 \%$. Consequently, the calculated mercury-effective pore volume varies from 0.008 to $0.049 \mathrm{~cm}^{3}$ with an average of $0.034 \mathrm{~cm}^{3}$ in per unit $\left(\mathrm{cm}^{3}\right)$ of rock; and the effective throat volume varies from 0.012 to $0.026 \mathrm{~cm}^{3}$ with an average of $0.017 \mathrm{~cm}^{3}$ in per unit $\left(\mathrm{cm}^{3}\right)$ of rock. The calculated equivalent pore and throat radii in each sample distributed was illustrated in Figures 5(a) and 5(b) representatively. The value of pore radius mainly lies between 100 and $200 \mu \mathrm{m}$, and the throat radius is mainly between 0.1 and $0.6 \mu \mathrm{m}$. The average pore and throat radius in each sample varies from 154 to $166 \mu \mathrm{m}$ (average $162 \mu \mathrm{m}$ ) and from 0.26 to $0.47 \mu \mathrm{m}$ (average $0.32 \mu \mathrm{m}$ ). Standard deviation coefficient of throat radius in each sample was calculated as a parameter to evaluate the heterogeneity of throat size in these samples. The average standard deviation coefficient of each sample varies from 0.22 to 0.35 with an average of 0.27 . RMICP that separated pore and throat volume allows that pore/throat ratio can be calculated, which is an important parameter to analyze the characteristics of distribution of pores and throats. The average pore/throat ratio of each sample ranges from 405 to 764 (average is 575). Some examples of pore/throat ratio distribution in individual samples are shown in Figure 5(c); they are mainly located in between 200 and 800 .

4.3. Nuclear Magnetic Resonance (NMR). NMR experiment records $T_{2}$ and its amplitude of the samples both in water saturation and in centrifuged condition. The curve of $T_{2}$ and its amplitude shows a weak bimodal when the samples are saturated. Comparing to the curve that was centrifuged, the decrease of amplitude in the right, which has long $T_{2}$ and results from pores mainly, shows that most movable water came from the pores, and the left of the curve changed slightly, which shows that the throats held water firmly (Figure 6). The statistic results reveal the percentage of irreducible and movable water in these samples (Table 1). Movable water has a proportion of 30 to $56 \%$ with an average of $40 \%$. On the contrary, irreducible water has a proportion of $60 \%$ in average and reaches a maximum of $70 \%$. Calculated with the rock porosity, only three to six percent of the whole rock bulk volume is available for hydrocarbon production (Table 1).

The volume of movable water is different to the RMICP result of mercury saturation volume. The movable water could flow freely in the reservoir or at high pressure (e.g., provided by stimulation production technique). Mercury injected under the high pressure can be interpreted as the volume of hydrocarbon that could be preserved in the reservoir, but not all of them could be produced. One thing needs to be understood here is that the cohesiveness and adhesiveness of water, mercury, and hydrocarbon are different significantly, so that the comparison analysis between the saturation results of these two experiments is not scientific; however, the analysis of individual experiment results or comparison of the geometry parameter is still a useful technique for understanding pore and throat structure of the hydrocarbon reservoir.

\section{Discussion}

5.1. The Influence of Pore-Throat Geometry on Porosity and Permeability. The weak relationship between core analysis porosity and permeability indicated that the porosity of these tight reservoirs inappreciably impacts on permeability, implying that the permeability of tight reservoir was controlled by the other factors (Figure 3).

The pore-throat geometry is derived from or revealed by RMICP parameters. The previous researches have been dedicated to the correlation of MICP parameters, mainly mercury saturation and capillary pressure, and reservoir permeability [66-69]. Swanson parameter and capillary parachor, two parameters derived from MICP, have a positive correlation to permeability value in both coarse and tight sandstone [67, 69]. However, irrespective of the applicability, these parameters are empirical correlation of the experiment data and the reservoir porosity and permeability. The essential relation between pore-throat structure and reservoir capability needs to be further investigated.

The cross-plot of calculated pore radius and porosity and permeability in these tight reservoirs indicate that pore size weakly impacts on both porosity and permeability (Figures $7(\mathrm{a})$ and $7(\mathrm{~b})$ ). Throat size and volume perform differently to permeability. The throat radii have slightly positive correlation to permeability (Figure 7(c)), but its volume impacts on porosity negligibly (Figure $7(\mathrm{~d})$ ). The average value of pore/throat ratio has a negative correlation to the value of permeability, which suggests that the relative volume of throat controls reservoir permeability, and it seems more crucial than throat radius (Figures $7(\mathrm{c})$ and $7(\mathrm{e})$ ). Porosity has a reverse correlation to the average pore/throat ratio; it seems plausible that relatively more pore volume than throat volume 


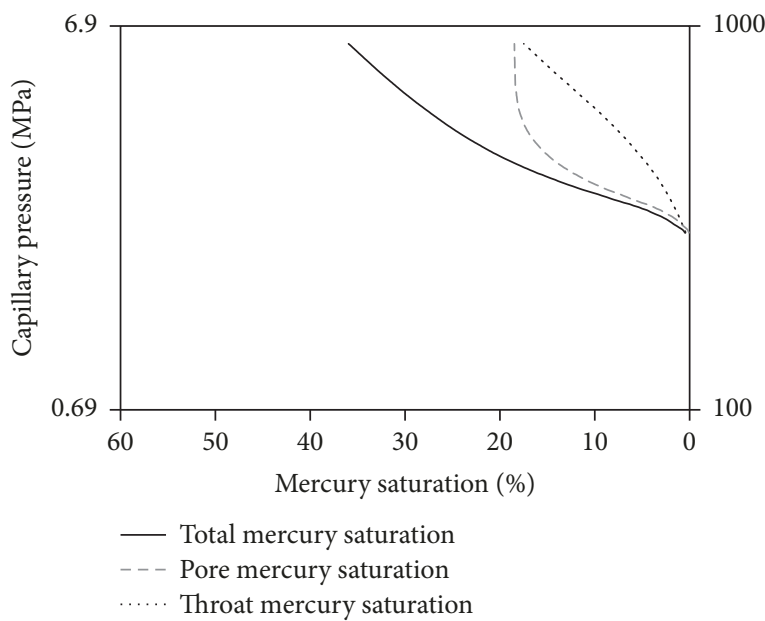

(a)

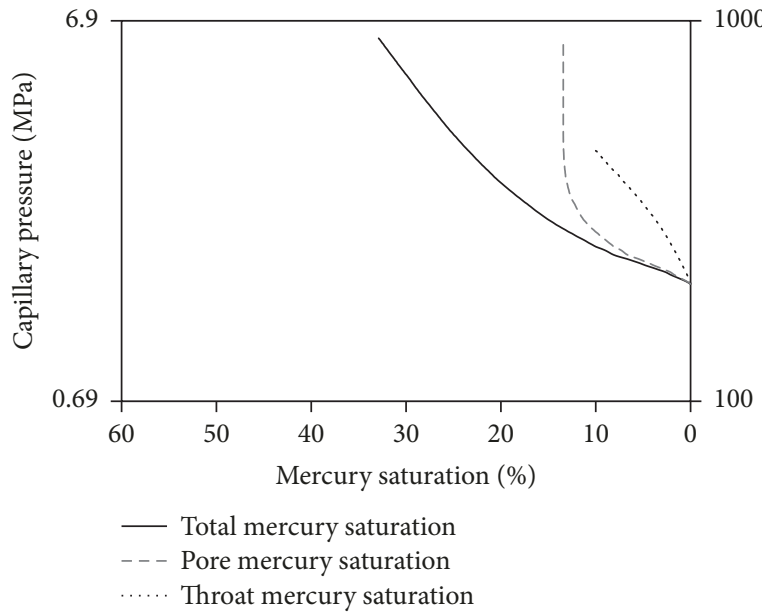

(c)

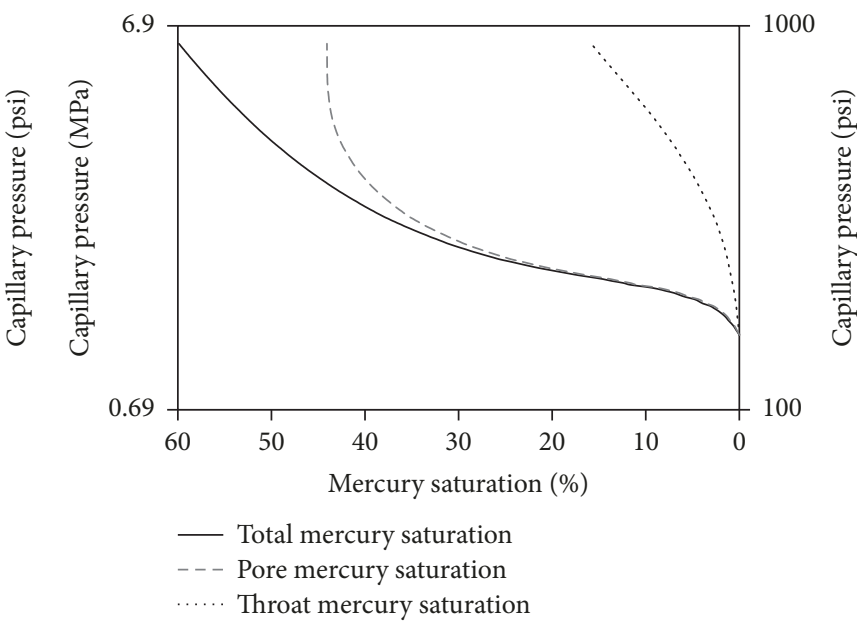

(b)

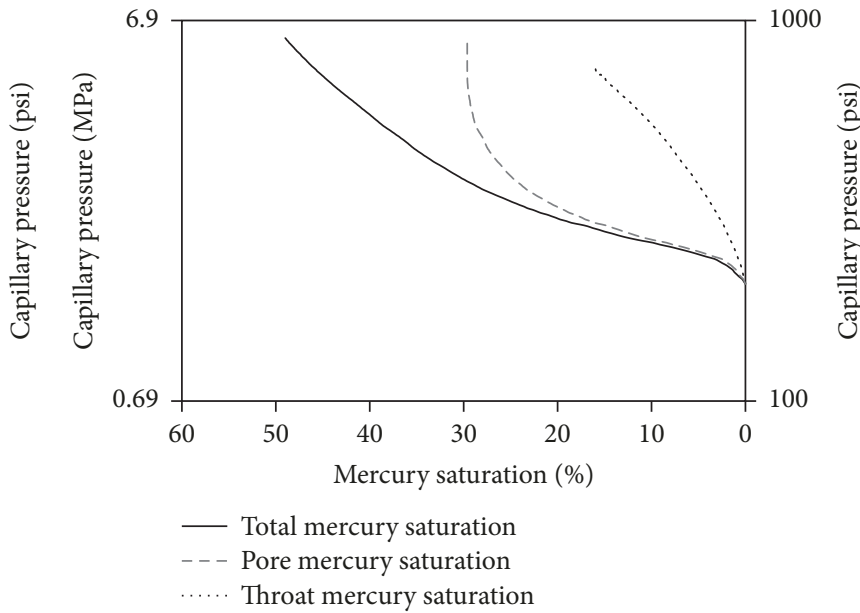

(d)

FIgURE 4: Typical capillary curve plotted with the mercury saturation of the tight clastic rock samples from Upper Triassic Chang 7 Member, Odors Basin. (a) The sample has high threshold pressure (z-8); (b) the sample has low threshold pressure and high mercury saturation (z-3); (c) the sample has low mercury saturation (z-11); (d) the sample has intermediate threshold pressure and mercury saturation (z-7).

is beneficial to bulk porosity. However, the bulk porosity is defined as the volume proportion of pore and throat in per unit of rock; there is no substantial correlation between their ratio and porosity (Figure $7(\mathrm{f})$ ). Consequently, the reality correlation between pore/throat ratio and porosity implies that there may have a link between rock and porosity and pore-throat structure.

Standard deviation coefficient of throat radius reveals the homogeneous degree the throats in size. Its relationship with the permeability indicates that permeability of these tight reservoirs is determined by the throat size distribution significantly (Figure 8(a)). Empirically, permeability is mainly contributed by the part of larger throats and the increase of smaller throats in proportion decreases the permeability [28]. Comparing the throat radius distribution and the corresponding contribution to the permeability between the samples having different permeability value indicates that high permeability sample has more large throats, and the permeability result from the relative larger throat dominated the total permeability (Figure $8(\mathrm{~b})$ ). The mathematical homogenization of the throat size shows that the samples that are more heterogeneous in throat size have more relatively large throats and higher permeability value. Oppositely, more homogeneity accounts for a narrow range of throat radius, and the majority of throat radii are small, which is a disadvantage to fluid flow (Figure 8(b)). Therefore, permeability has a negative correlation to the homogeneity of throat radius distribution, and the relative larger throats dominated the permeability of the tight clastic rock reservoir. To research the most valuable throat size to permeability, the $80 \%$ of priority permeability was investigated. In the experiment of mercury injection, mercury enters the larger throat easily and preferentially. The large throats that created $80 \%$ of bulk permeability have been counted. Here the permeability is mercury injection permeability; it may have slight difference to air, hydrocarbon, or other fluid permeability. The result shows that the throat radii that result in $80 \%$ permeability of samples varies from about 0.2 to $0.7 \mu \mathrm{m}$, 

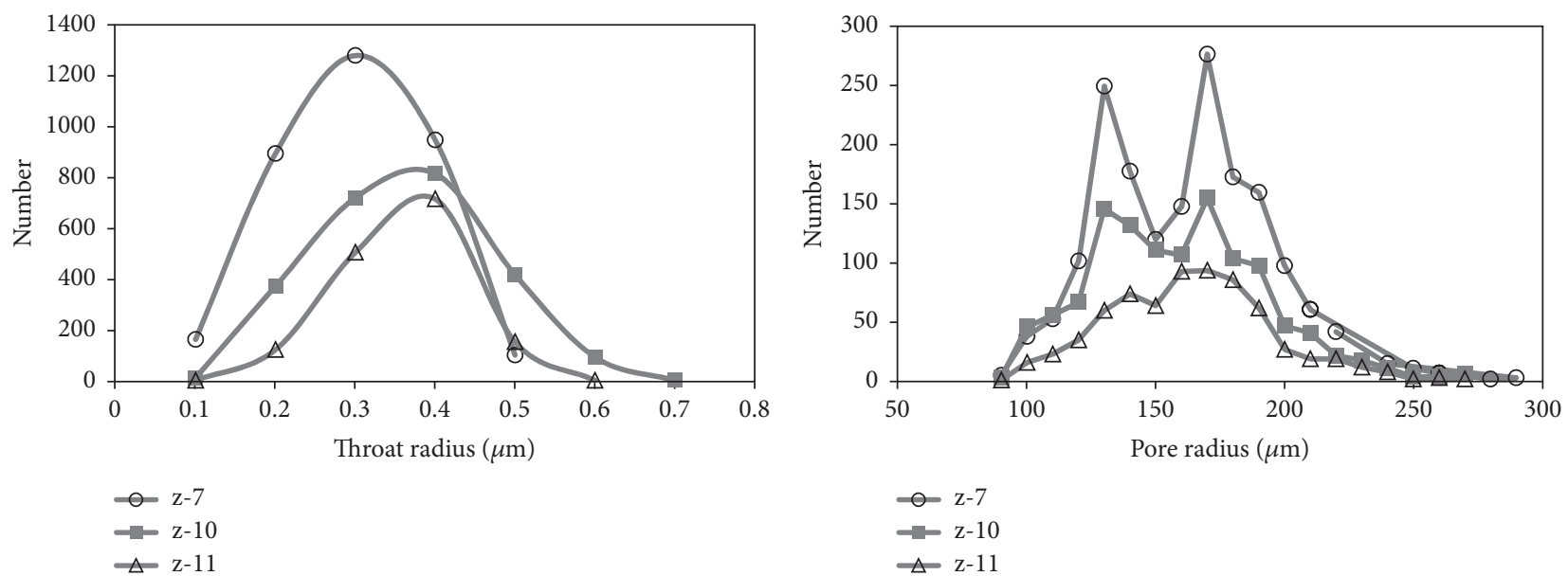

(a)

(b)

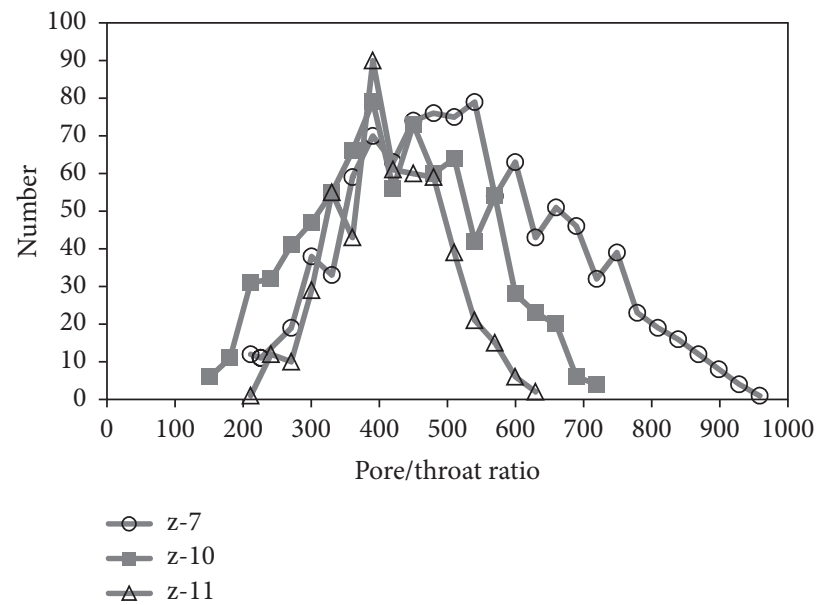

(c)

Figure 5: The example of the distributional characteristics of throat (a), pore (b) radius, and pore/throat ratio (c) in the tight clastic rock samples from Upper Triassic Chang 7 Member, Odors Basin.

and this portion of throats cover more wide range and have relative larger value in the samples that have relative high permeability (Figure 9). The statistic shows that this portion of throats are less than $33 \%$ of the total throats in volume with an average of $22 \%$ (Figure 9). Therefore, about twenty percent of throats that have large radius value dominated the rock's effective permeability generally. We realize that the minimum throat radius is limited to $0.12 \mu \mathrm{m}$ by the experiment; we can firmly refer to the fact that there are more throats beyond our experiment, which have smaller radius than $0.12 \mu \mathrm{m}$. This suggests that the result of about twenty percent is just confined in the experiment data. This reveals that the throat radius covers a very wide range, which is from the largest radius to nanoscale that less than $0.12 \mu \mathrm{m}$, and the distribution patterns of the throat radius that result in permeability are highly similar (Figure $8(\mathrm{~b})$ ), which suggests that the largest throat radius is crucial to throat community in the samples.

The largest throat radius could be deciphered by threshold pressure, and high threshold pressure suggests small maximum throat radius, vice versa. The correlation of threshold (maximum) throat radius to the average throat radius and standard deviation coefficient of throat radius shows that the average throat radii are mostly dominated by the maximum throat radius value (Figure 10(a)) and the low value of maximum throat radius results in a relative narrow mathematical distribution of throat radius and further low permeability (Figures 10(b) and 10(c)).

5.2. The Storage Capability Estimated by RMICP. Porosity is the percentage of the space in bulk rock that was not occupied by the rock mineralogical component. However, the theoretic porosity is hard to be identified practically but was measured by undirected ways of fluid injection. Therefore, the used porosity data is a relative value to particular fluid, such as helium and mercury, as well as permeability. Generally, effective porosity for hydrocarbon is more similar to that for mercury, and helium porosity is more close to theoretic value. The experiment of RMICP reoccurred in the fluid flow processes in the porous rock by mercury and finally recorded the storage capability of these tight reservoirs for mercury by saturation. And this capability could be deduced to for 

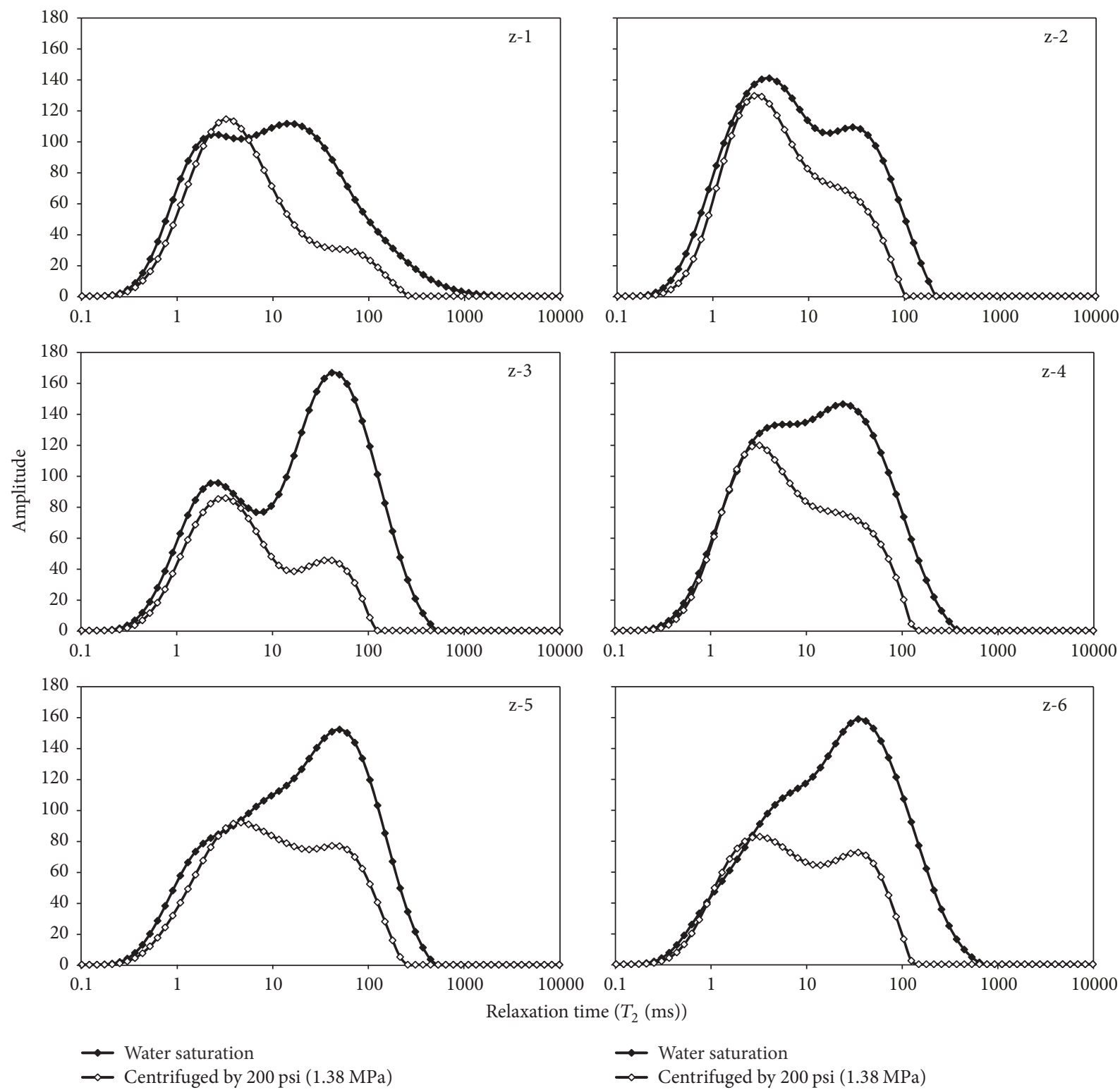

Relaxation time $\left(T_{2}(\mathrm{~ms})\right)$

$\sim$ Centrifuged by $200 \mathrm{psi}(1.38 \mathrm{MPa})$

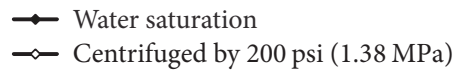

FIgURE 6: The curve of relaxation time $T_{2}$ and its amplitude result from NMR experiment of the tight clastic rock samples from Upper Triassic Chang 7 Member, Odors Basin.

hydrocarbon fluid analogically. Here we addressed the controls on this capability by analyzing the pore-throat structure. To find the proportion of pore and throat space that works for mercury saturation separately, the mercury saturation in them was cross-plotted to the total mercury saturation of the sample (Figure 11). The results indicate that effective pores dominated the increase of the total mercury saturation, and the valid throat space has a relatively steady value (Figure 11 ). The statistic shows that more than $5 \%$ of bulk volume is effective space to be as reservoir; about $3 \%$ results from pores, and the other $2 \%$ from throats generally (Table 1 ). Comparison to the helium porosity shows that less than fifty percent of porosity is efficient for mercury. In the other way round, more than fifty percent of pore-throat space has negligible contribution to the hydrocarbon storage in tight clastic rock reservoir.
The correlation analysis illustrates that porosity and permeability have a weak controls on mercury saturation, and the mercury injected pore-throat space is treated as valid porosity for hydrocarbon storage (Figures 12(a) and 12(b)). The parameters of pore-throat geometry parameters include pore and throat radius, throat size distribution, and pore/throat ratio, individually impacting on the valid porosity insignificantly (Figures 12(c), 12(d), 12(e), and 12(f)). However, the physical characteristics, particularly the porethroat structure, are the critical factor for fluid flow and keep in the rock, and thus there must exist an indetectable relation behind these parameters, which controls the valid porosity comprehensively. Four pore-throat geometry parameters, including total porosity, threshold throat radius, standard deviation coefficient of throat radius, and pore/throat ratio, which contains total pore space in the rock, the determining 


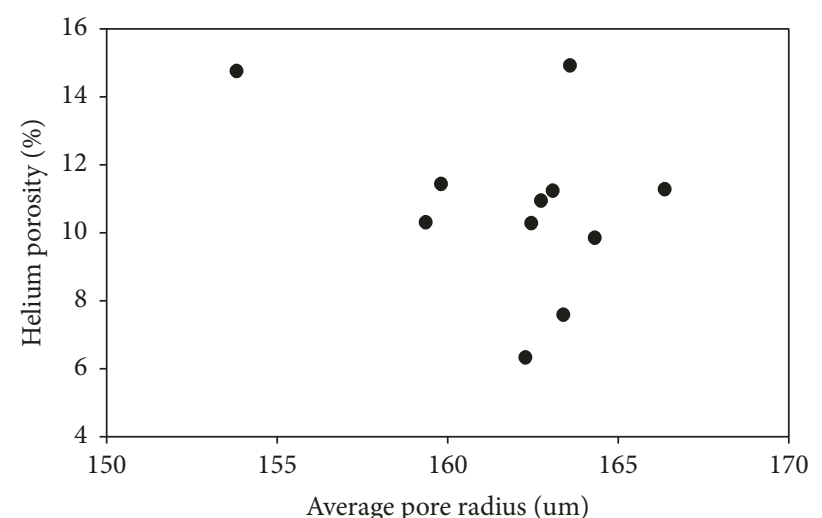

(a)

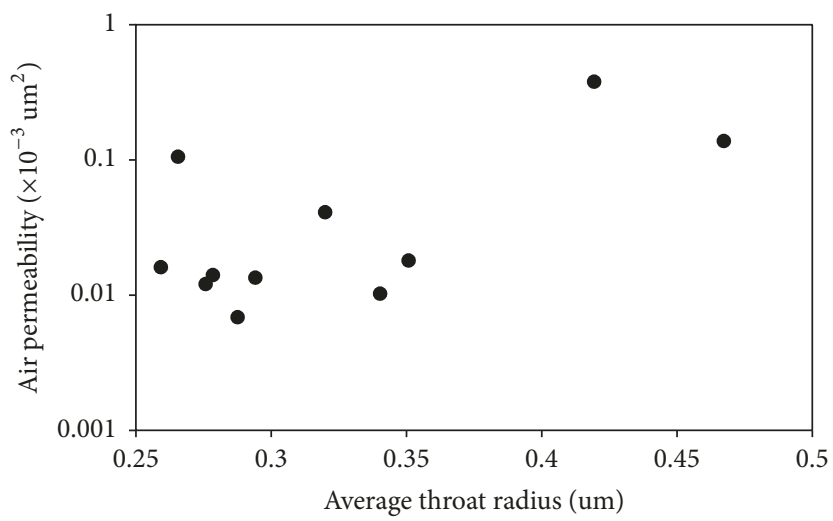

(c)

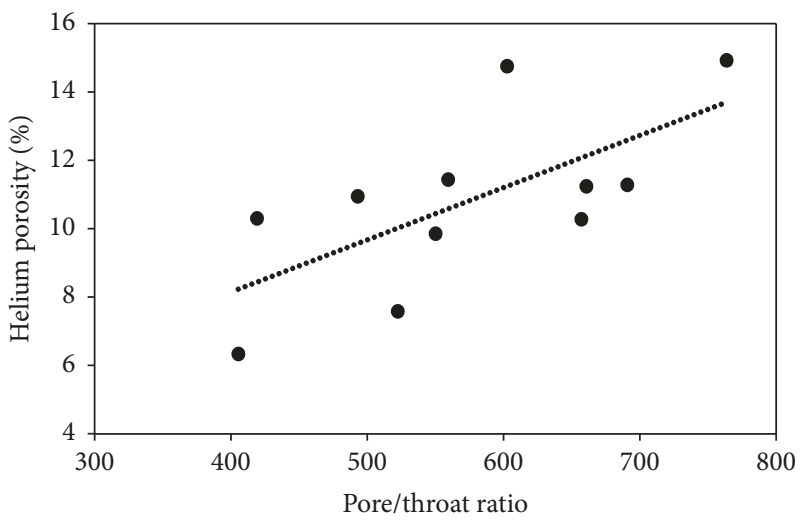

(e)

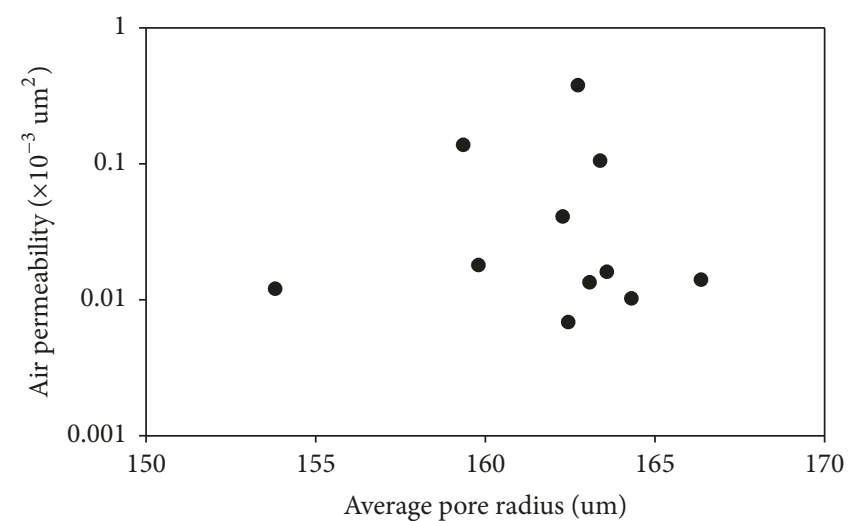

(b)

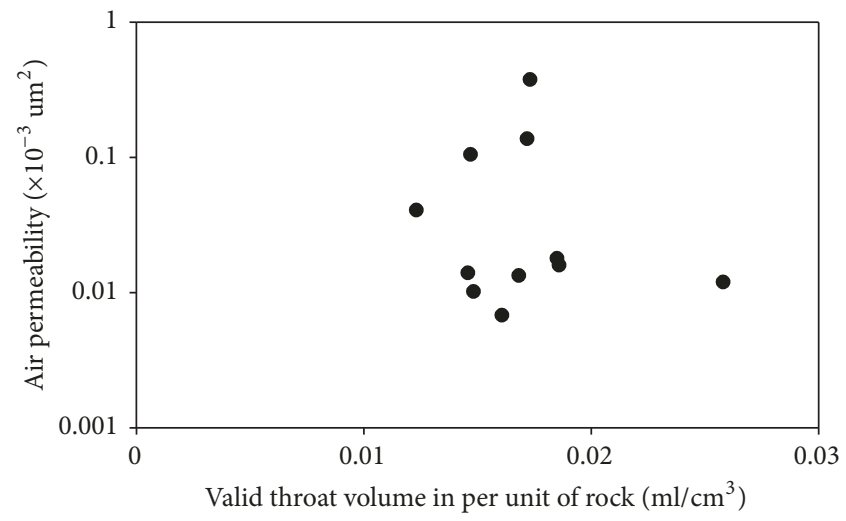

(d)

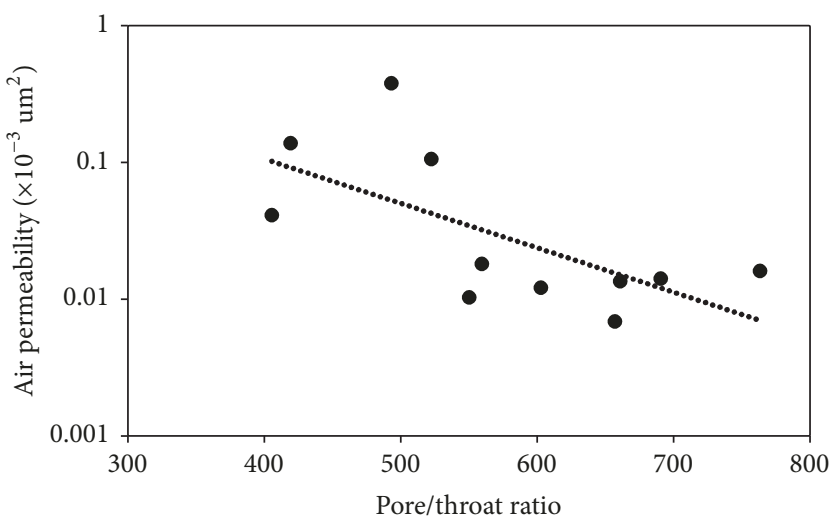

(f)

FIGURE 7: The correlation of pore-throat parameters and porosity and permeability of the tight clastic rock samples from Upper Triassic Chang 7 Member, Odors Basin.

factor for fluid flow and the relation between pore and throat space value, were integrated to establish a combination parameter that characterized the pore-throat structure integrated. The result shows two different regression correlations between combination parameter ( $\varepsilon$, detailed in Figure 13 and caption) and the mercury saturation (the proportion of valid porosity) (Figure 13). These two parts of samples were separated by the mercury saturation value of about $45 \%$. However, they could be expressed by one equation:

$$
S_{\mathrm{Hg}}=a e^{b \varepsilon},
$$

where $S_{\mathrm{Hg}}$ is mercury saturation; $a$ and $b$ are constants determined by the available proportion of pore and throat space for mercury. Lower than $45 \%$ of mercury saturation suggests that more percentage of porosity is unavailable for mercury, implying that the pore-throat structure of the rock is intricate. Therefore, this separation may associated with the physical properties of mercury (e.g., coherence and adherence stress) and/or other characteristics linked to more complicated porethroat structure of rock itself, which is hard to be tested by RMICP. 


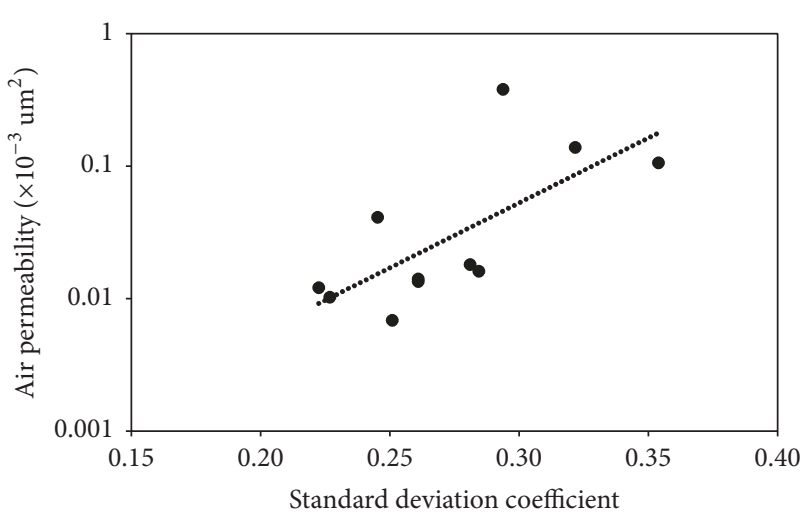

(a)

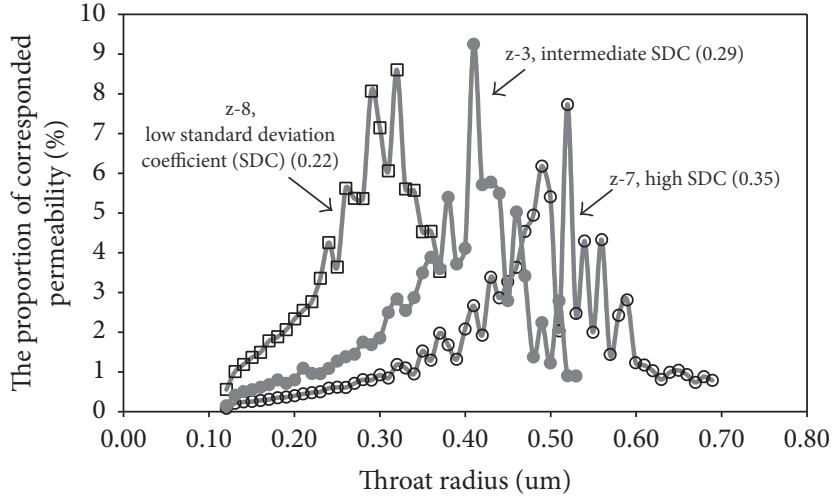

(b)

FIgURE 8: The correlation of throat and permeability of the samples from the Upper Triassic Chang 7 Member, Odors Basin. (a) Correlation of standard variation coefficient of the throat radii and permeability; (b) the curve of throat radii and the permeability value that result from, correspondingly, the three curve presenting high, low, and intermediate standard deviation coefficient, which stand for high, low, and intermediate heterogeneity degree of the throat radii in mathematical distribution.

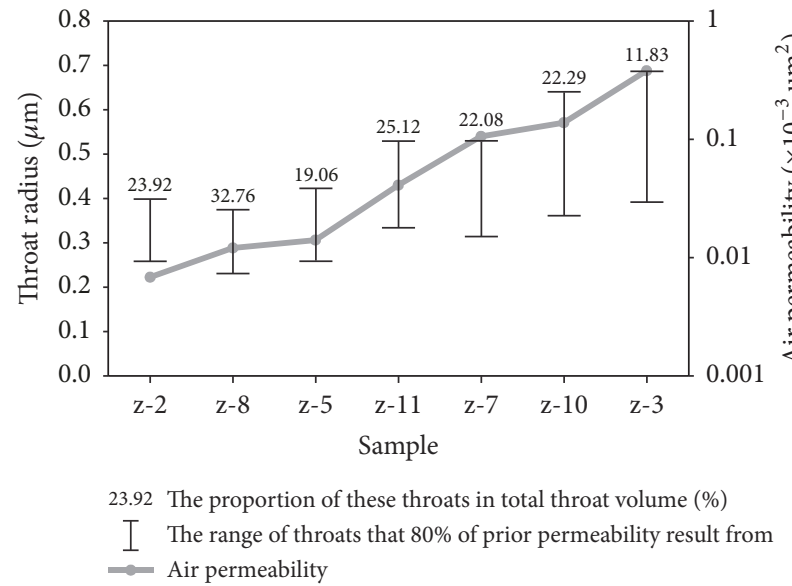

FIGURE 9: The relationship between throat radius and air permeability of the samples from Upper Triassic Chang 7 Member, Odors Basin. The prior permeability $(80 \%)$ results from a small portion of large throats, and the trend of air permeability has a close relationship with the radii of the large throats.

5.3. The Controls of Movable Fluid in Tight Clastic Rock Reservoir. NMR experiment allows the volume of movable and irresistible fluid (water) in the reservoir to be calculated from $T_{2}$. The movable water here was defined as that could outflow from the rock under the centrifugal force of $200 \mathrm{psi}$ $(1.38 \mathrm{MPa})$ that is set in the experiment. This condition is different to the mercury injection processes, which reached $900 \mathrm{psi}(6.21 \mathrm{MPa})$. This may be a reason for the difference between volume of mercury saturation test by RMICP and movable water saturation from NMR.

Mercury and water have an about ten times difference in viscosity (assuming the temperature of $25^{\circ} \mathrm{C}$ ). Therefore the effective radius and volume of pore and throat are different for water and mercury. However, the correlation of pore-throat radius and capillary pressure just associated with the fluid and fluid-solid characteristic ( $\gamma$ and $\theta$ ), which is a constant for specific fluid and porous materials. Consequently, the porethroat parameters for water flow in the samples have a fixed proportionality constant with that calculated by mercury experiment. So the correlation investigation between the pore-throat structures result from RMICP and water saturation result from NMR is reasonable and effective.

The comparison analysis indicates that the movable water in these tight reservoirs has a good correlation to a lot of pore-throat parameters except for pore radius (Figure 14(a)). The positive correlation of air permeability and average throat radius to movable water saturation indicates that high air permeability and larger throat radius are beneficial for fluid flowing in the reservoir and lead to high movable water saturation (Figures 14(b) and 14(c)), and the portion of large throats dominated this correlation, which could be indicated by the positive correlation of movable water saturation to standard deviation coefficient of throat radius and particularly maximum throat radius, which shows more closely relation to movable water saturation with correlation coefficient of 0.97 (Figures 14(d) and 14(e)). The pores actually 


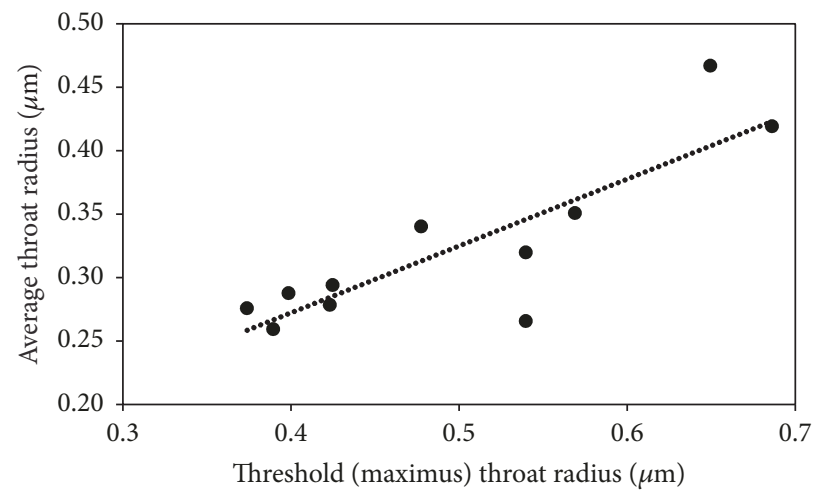

(a)

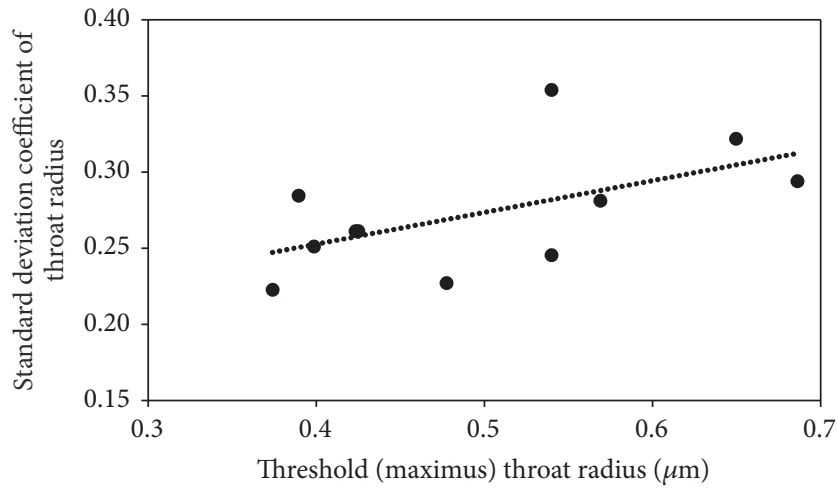

(b)

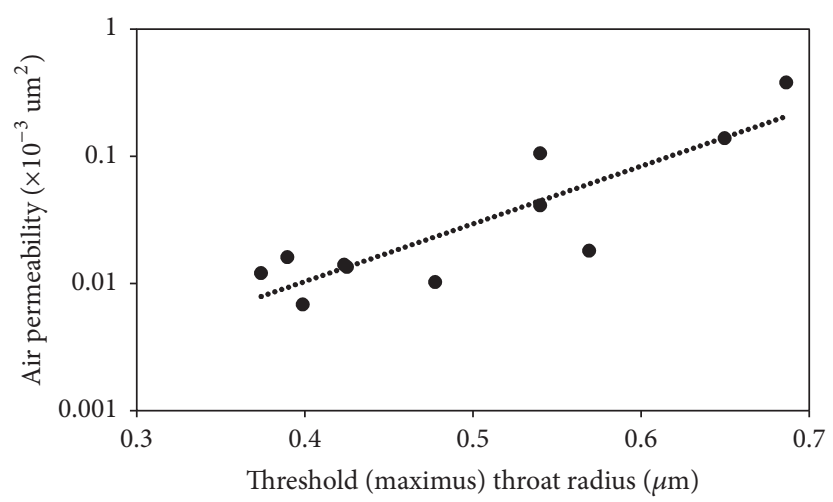

(c)

FIGURE 10: The correlation of threshold (maximum) throat radius to the distribution of the throat radii and permeability of the samples from Upper Triassic Chang 7 Member, Odors Basin.

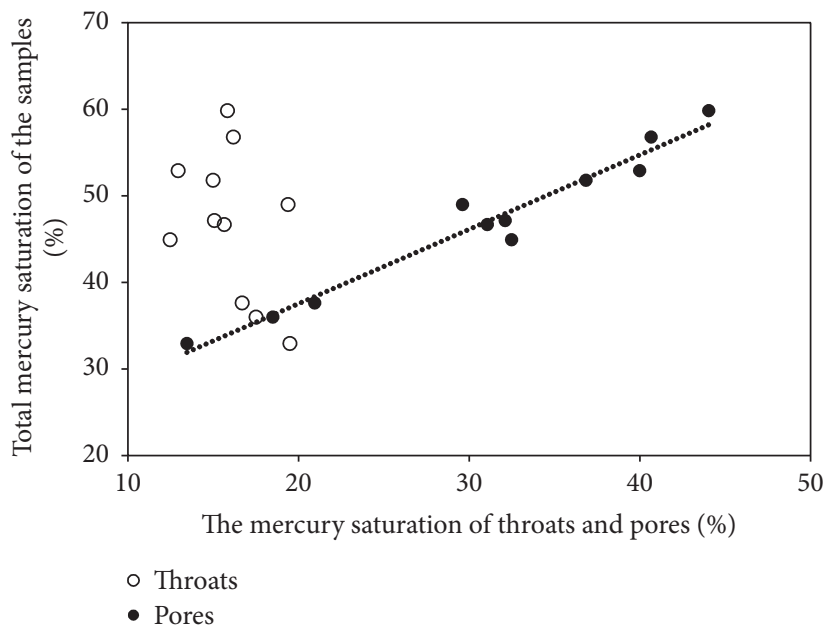

FIGURE 11: The correlation of total mercury saturation and the portion from throats and pores, implying the portion of valid porosity that result from throats and pores separately.

impact on the movable water saturation as it is mainly space for water storage. However, it is constrained by the relative volume of throats, which was demonstrated by the negative correlation of pore/throat ratio and movable water saturation (Figure 14(f)).

5.4. Irresistible Water in Tight Clastic Rock Reservoir. Most of preserving and producing petroleum clastic rock reservoirs are hydrophilic, and thus the capability of the rocks on holding irresistible water is a key factor of percolation threshold, capillary pressure, permeability, and available pore-throat space of petroleum reservoir [70, 71]. Here we focused on the pore-throat structure impacting on irresistible water saturation by using of NMR.

The positive correlation between movable water saturation and threshold throat radius indicates that the fluid 


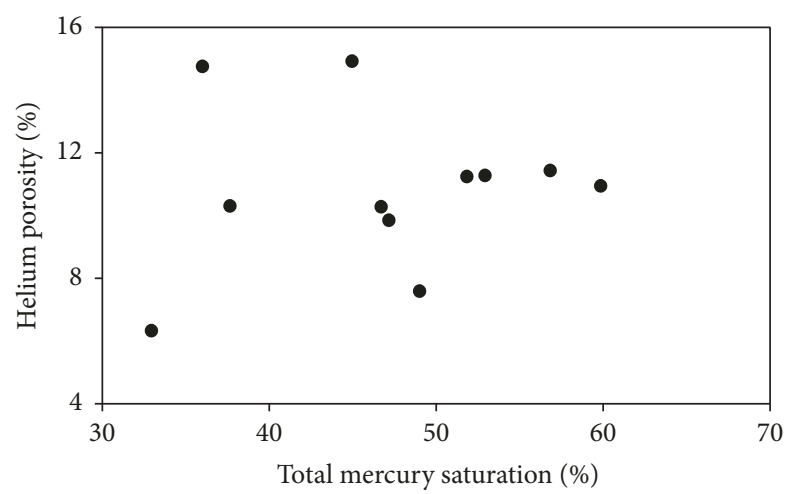

(a)

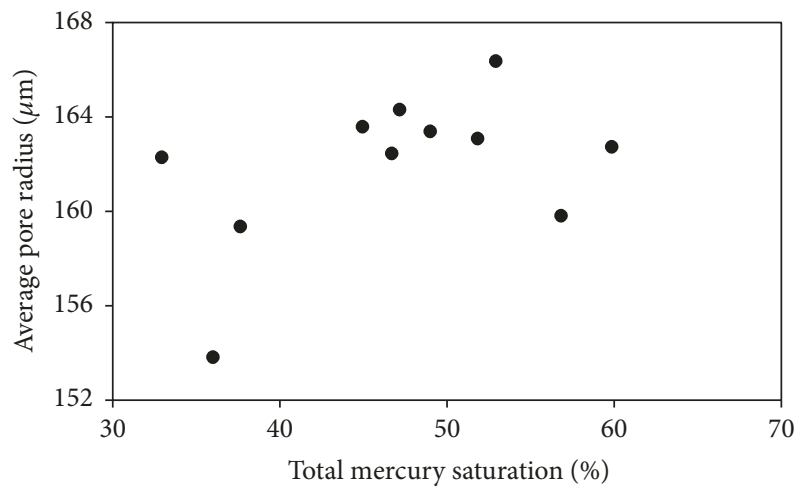

(c)

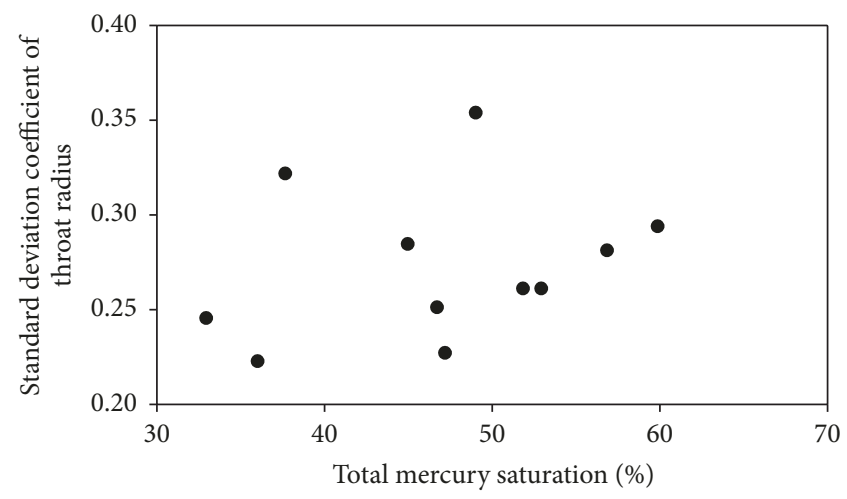

(e)

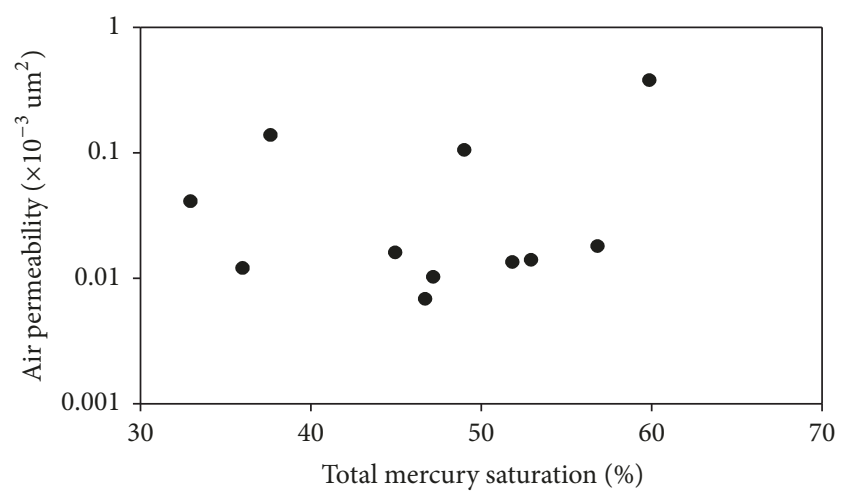

(b)

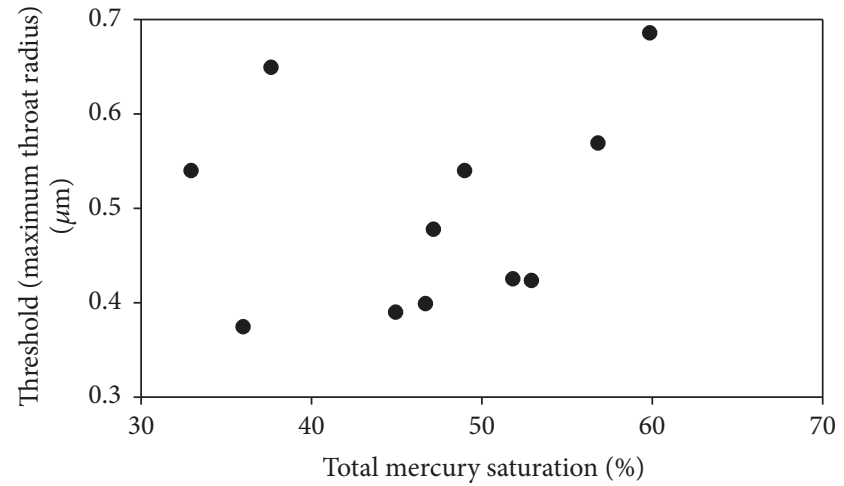

(d)

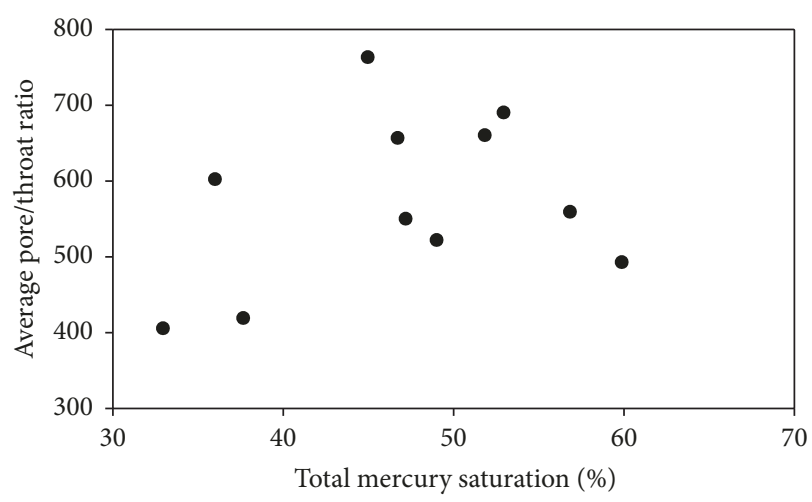

(f)

FIGURE 12: The correlation of pore-throat structure parameters and total mercury saturation of the samples from Upper Triassic Chang 7 Member, Odors Basin.

flow in the tight reservoir was controlled by permeability (Figures 10(c) and 14(e)). However, the irresistible water saturation is not controlled by the largest throat, but the opposite, the small throat. Additionally, the network of the pore-throat in the reservoir also influences the water that was held by the reservoir. As Barsotti et al. [6] summarized, in the tight reservoir, confined space of pore-throat network resulted in large intermolecular forces, and, consequently, the function of fluid-pore-wall interactions influence the phase behavior more significantly. Capillary and adsorptive forces alter phase boundaries, phase compositions, interfacial tensions, fluid densities, fluid viscosities, saturation pressures, the coordination number of throats and pores, orientation of throat, and fluid wettability characteristic [72]; the composition, for example, clay minerals [3], become more effective on fluid flow in the bulk. Fluid physical properties are qualitatively known to influence the performance of confined fluids except for pore-throat structure [73-76]. As we mentioned above, the difference that resulted from the particular fluids which was used in the experiment can be eliminated by a fixed proportionality constant for the same porous materials even if they have different wettability. Therefore, the correlation analysis of $\varepsilon$ and irresistible water saturation are reasonable in particular samples. The correlation between irresistible 


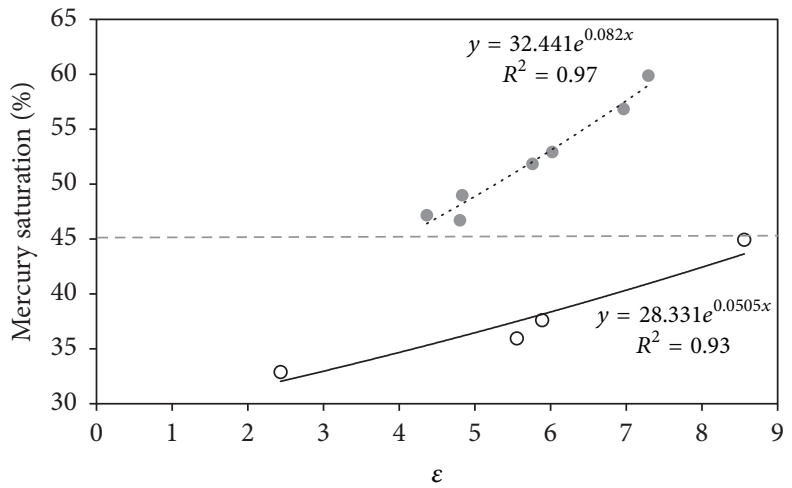

FIgURE 13: The correlation of the combination parameter of pore-throat structure $(\varepsilon)$ and total mercury saturation. This implies the relationship between pore-throat structure and valid porosity of the reservoir. The detail of $\varepsilon$ refers to the footnote of Table 1 .

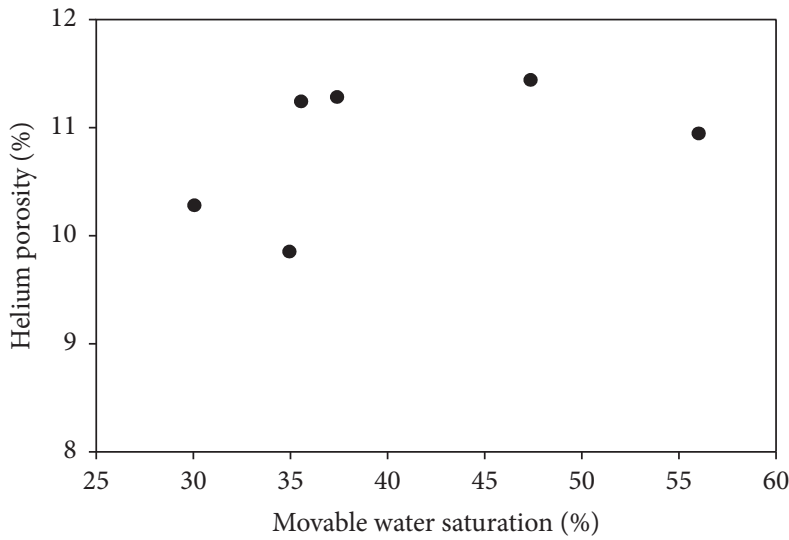

(a)

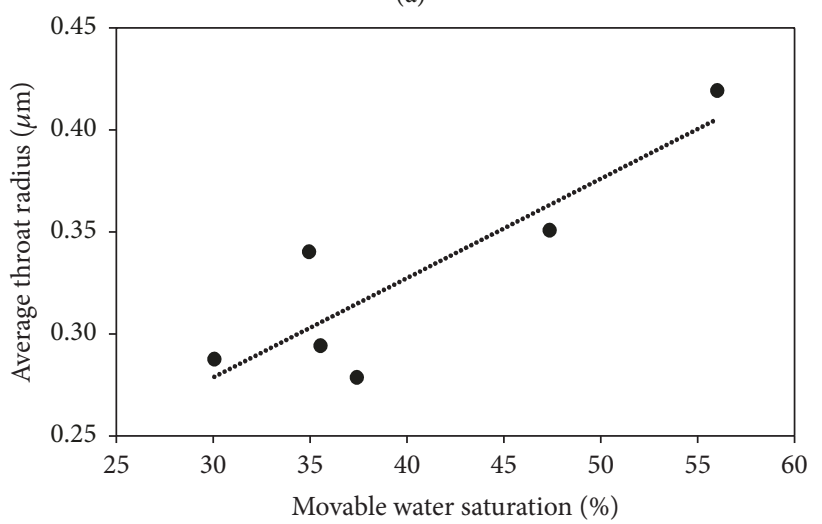

(c)

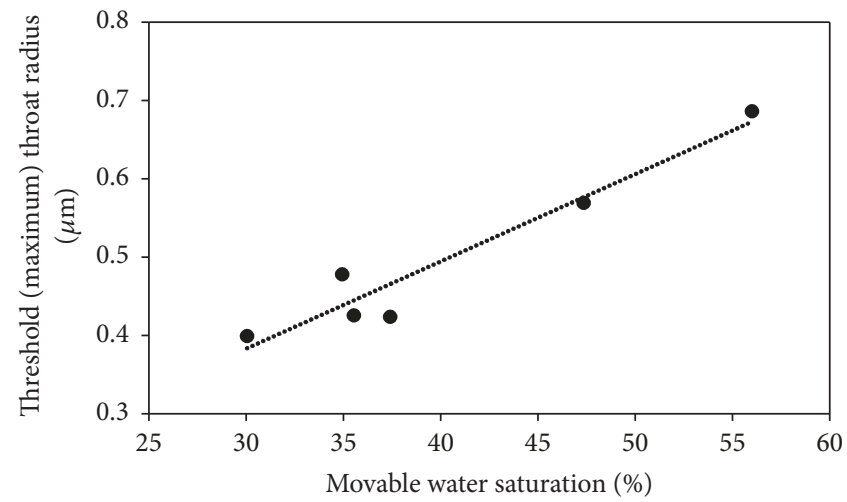

(e)

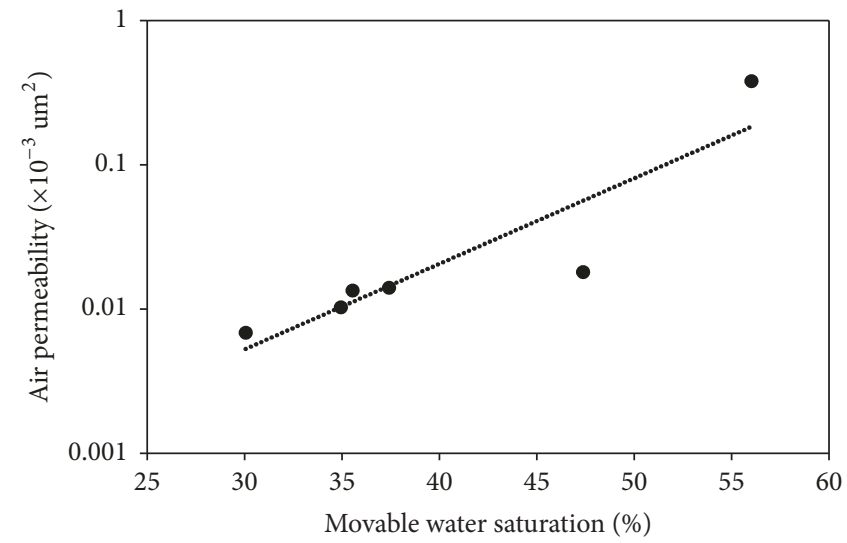

(b)

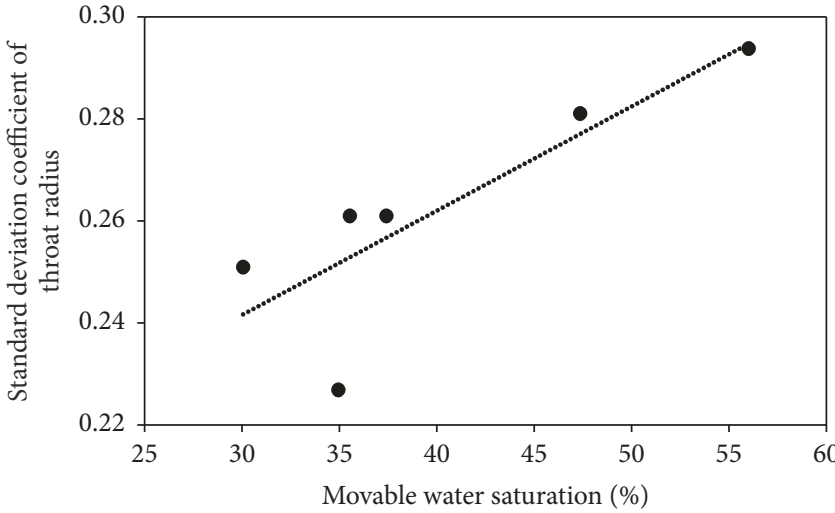

(d)

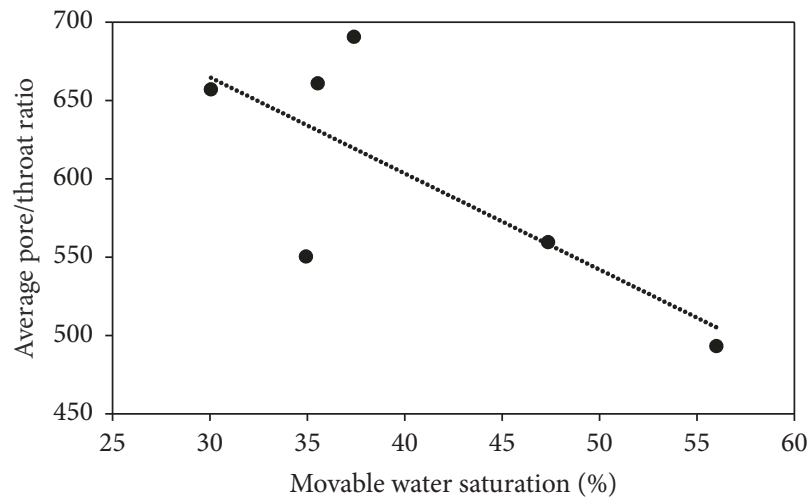

(f)

FIGURE 14: The correlation of pore-throat parameters and movable water saturation indicate that movable water saturation has a close relationship with throat geometry, which determined the permeability of the reservoir. 


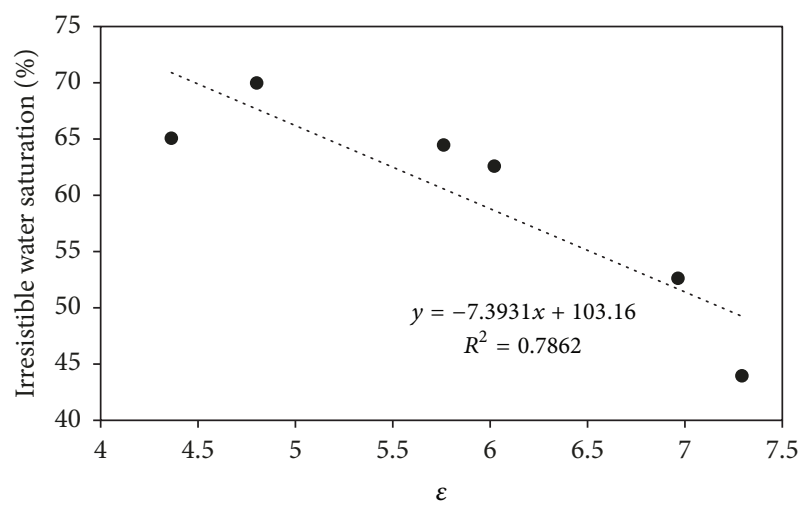

FIGURE 15: The correlation of the combination parameter of porethroat structure $(\varepsilon)$ and irresistible water saturation. The detail of $\varepsilon$ refers to the footnote of Table 1.

water saturation and $\varepsilon$ indicates that the pore-throat structure combination parameter $(\varepsilon)$ controls irresistible water saturation mainly (Figure 15). The value of the irresistible water saturation is the proportion of pore and throat space that is occupied by water (wetting phase) and therefore is negligible for injection or drainage of petroleum. Combined with the talk above, we can infer that pore-throat structure is the key control on fluid flow and holds in tight clastic reservoir and the function of $\varepsilon$ can be used to characterize the pore-throat structure in the tight clastic reservoir significantly.

\section{Conclusion}

The portion of throats that have relatively large radius controlled the average value and mathematical distribution pattern of throat radii in the whole bulk rock. The permeability of the reservoir is significantly dominated by the radius value of the largest throat.

The porosity of the tight clastic rock reservoir is associated with the comprehensive function of the pore-throat structure. High value of pore/throat ratio presents a positive effect on porosity.

Although the increase of the porosity is determined by the pore bodies, the space volume of throats contributes to the bulk porosity in a relatively high proportion in the tight clastic rock reservoir. The valid porosity for fluid seems weakly impacted by any single physical parameters of the reservoir; it is positively associated with the combination function of pore-throat structure.

A high proportion of porosity is invalid for hydrocarbon in tight clastic rock reservoir. Relatively high permeability results in a relatively high movable water saturation (net pay) potentially.

Pore-throat structure, as was characterized by the combination parameter $(\varepsilon)$, is the key controls of the fluid performance in the tight clastic reservoir, and thus $\varepsilon$ is a reasonable predictor of reservoir quality.

\section{Conflicts of Interest}

The authors declare that there are no conflicts of interest regarding the publication of this paper.

\section{Acknowledgments}

The authors acknowledge the financial and research materials support of Changqing Oilfield of PetroChina (COPC) gratefully. They thank Senior Engineer Zhengping Fan for collection of the data,and acknowledge the operation of Research Institute of Petroleum Exploration \& Development, CNPC, for testing the samples.

\section{References}

[1] T. Cao, Z. Song, S. Wang, X. Cao, Y. Li, and J. Xia, "Characterizing the pore structure in the Silurian and Permian shales of the Sichuan Basin, China," Marine and Petroleum Geology, vol. 61, pp. 140-150, 2015.

[2] H. P. Menke, B. Bijeljic, M. G. Andrew, and M. J. Blunt, "Dynamic three-dimensional pore-scale imaging of reaction in a carbonate at reservoir conditions," Environmental Science and Technology, vol. 49, no. 7, pp. 4407-4414, 2015.

[3] E. Rosenbrand, I. L. Fabricius, Q. Fisher, and C. Grattoni, "Permeability in Rotliegend gas sandstones to gas and brine as predicted from NMR, mercury injection and image analysis," Marine and Petroleum Geology, vol. 64, pp. 189-202, 2015.

[4] H. Saboorian-Jooybari and P. Pourafshary, "Significance of non-Darcy flow effect in fractured tight reservoirs," Journal of Natural Gas Science and Engineering, vol. 24, pp. 132-143, 2015.

[5] M. J. Barnaji, P. Pourafshary, and M. R. Rasaie, "Visual investigation of the effects of clay minerals on enhancement of oil recovery by low salinity water flooding," Fuel, vol. 184, pp. 826835, 2016.

[6] E. Barsotti, S. P. Tan, S. Saraji, M. Piri, and J.-H. Chen, "A review on capillary condensation in nanoporous media: Implications for hydrocarbon recovery from tight reservoirs," Fuel, vol. 184, pp. 344-361, 2016.

[7] S. Ergun and A. A. Orning, "Fluid flow through randomly packed columns and fluidized beds," Industrial and Engineering Chemistry, vol. 41, pp. 1179-1184, 1949.

[8] S. Whitaker, "The Forchheimer equation: a theoretical development," Transport in Porous Media, vol. 25, no. 1, pp. 27-61, 1996.

[9] E. W. Washburn, "The dynamics of capillary flow," Physical Review A: Atomic, Molecular and Optical Physics, vol. 17, no. 3, pp. 273-283, 1921.

[10] M. Josh, L. Esteban, C. Delle Piane, J. Sarout, D. N. Dewhurst, and M. B. Clennell, "Laboratory characterisation of shale properties," Journal of Petroleum Science and Engineering, vol. 88-89, pp. 107-124, 2012.

[11] A. Dillinger and L. Esteban, "Experimental evaluation of reservoir quality in Mesozoic formations of the Perth Basin (Western Australia) by using a laboratory low field Nuclear Magnetic Resonance," Marine and Petroleum Geology, vol. 57, pp. 455469, 2014.

[12] M. Tan, K. Mao, X. Song, X. Yang, and J. Xu, "NMR petrophysical interpretation method of gas shale based on core NMR experiment," Journal of Petroleum Science and Engineering, vol. 136, pp. 100-111, 2015.

[13] H. Gao and H. A. Li, "Pore structure characterization, permeability evaluation and enhanced gas recovery techniques of tight gas sandstones," Journal of Natural Gas Science and Engineering, vol. 28, pp. 536-547, 2016.

[14] H. Han, Y. Cao, S.-J. Chen et al., "Influence of particle size on gas-adsorption experiments of shales: An example from a 
Longmaxi Shale sample from the Sichuan Basin, China," Fuel, vol. 186, pp. 750-757, 2016.

[15] L. Xiao, C.-C. Zou, Z.-Q. Mao, Y. Jin, and J.-C. Zhu, "A new technique for synthetizing capillary pressure (Pc) curves using NMR logs in tight gas sandstone reservoirs," Journal of Petroleum Science and Engineering, vol. 145, pp. 493-501, 2016a.

[16] A. Y. Beliaev and R. J. Schotting, "Analysis of a new model for unsaturated flow in porous media including hysteresis and dynamic effects," Computational Geosciences, vol. 5, no. 4, pp. 345-368, 2001.

[17] R. Helmig, A. Weiss, and B. I. Wohlmuth, "Dynamic capillary effects in heterogeneous porous media," Computational Geosciences, vol. 11, no. 3, pp. 261-274, 2007.

[18] C. R. Clarkson, M. Freeman, L. He et al., "Characterization of tight gas reservoir pore structure using USANS/SANS and gas adsorption analysis," Fuel, vol. 95, pp. 371-385, 2012.

[19] R. Rezaee, A. Saeedi, and B. Clennell, “Tight gas sands permeability estimation from mercury injection capillary pressure and nuclear magnetic resonance data," Journal of Petroleum Science and Engineering, vol. 88-89, pp. 92-99, 2012.

[20] T. Jafari Behbahani, C. Ghotbi, V. Taghikhani, and A. Shahrabadi, "Investigation of asphaltene adsorption in sandstone core sample during CO2 injection: Experimental and modified modeling," Fuel, vol. 133, pp. 63-72, 2014.

[21] A. Z. Al-Yaseri, M. Lebedev, S. J. Vogt, M. L. Johns, A. Barifcani, and S. Iglauer, "Pore-scale analysis of formation damage in Bentheimer sandstone with in-situ NMR and micro-computed tomography experiments," Journal of Petroleum Science and Engineering, vol. 129, pp. 48-57, 2015.

[22] A. Ghanizadeh, C. R. Clarkson, S. Aquino, O. H. Ardakani, and H. Sanei, "Petrophysical and geomechanical characteristics of Canadian tight oil and liquid-rich gas reservoirs: I. Pore network and permeability characterization," Fuel, vol. 153, pp. 664-681, 2015.

[23] A. Sakhaee-Pour and S. L. Bryant, "Pore structure of shale," Fuel, vol. 143, pp. 467-475, 2015.

[24] Z. Hua, M. Li, X. Ni, H. Wang, Z. Yang, and M. Lin, "Effect of injection brine composition on wettability and oil recovery in sandstone reservoirs," Fuel, vol. 182, pp. 687-695, 2016.

[25] P. H. Nelson, "Pore-throat sizes in sandstones, tight sandstones, and shales," AAPG Bulletin, vol. 93, no. 3, pp. 329-340, 2009.

[26] X. Tian, L. Cheng, R. Cao et al., "A new approach to calculate permeability stress sensitivity in tight sandstone oil reservoirs considering micro-pore-throat structure," Journal of Petroleum Science and Engineering, vol. 133, pp. 576-588, 2015.

[27] H. Zhao, Z. Ning, Q. Wang et al., "Petrophysical characterization of tight oil reservoirs using pressure-controlled porosimetry combined with rate-controlled porosimetry," Fuel, vol. 154, pp. 233-242, 2015.

[28] K. Xi, Y. Cao, B. G. Haile et al., "How does the pore-throat size control the reservoir quality and oiliness of tight sandstones? The case of the Lower Cretaceous Quantou Formation in the southern Songliao Basin, China," Marine and Petroleum Geology, vol. 76, pp. 1-15, 2016.

[29] L. Xiao, C.-C. Zou, Z.-Q. Mao et al., "An empirical approach of evaluating tight sandstone reservoir pore structure in the absence of NMR logs," Journal of Petroleum Science and Engineering, vol. 137, pp. 227-239, 2016 b.

[30] A. J. Katz and A. H. Thompson, "Prediction of rock electrical conductivity from mercury injection measurements." Journal of Geophysical Research: Atmospheres, vol. 92, no. 1, pp. 599-607, 1987.
[31] Schowalter, "Mechanics of secondary hydrocarbon migration and entrapment," AAPG Bulletin, vol. 63, pp. 12174-12181, 1979.

[32] S. Kolodzie, "Analysis of pore throat size and use of the waxmansmits equation to determine ooip in spindle field colorado, 1980 ".

[33] E. D. Pittman, "Relationship of porosity and permeability to various parameters derived from mercury injection-capillary pressure curves for sandstone," The American Association of Petroleum Geologists Bulletin, vol. 76, no. 2, pp. 191-198, 1992.

[34] M. Spearing, T. Allen, and G. McAulay, "Review of the winland R35 method for net pay definition and its application in low permebility sands," in SCA, 2001.

[35] B. S. Nabawy, Y. Géraud, P. Rochette, and N. Bur, "Pore-throat characterization in highly porous and permeable sandstones," AAPG Bulletin, vol. 93, no. 6, pp. 719-739, 2009.

[36] J. H. Norbisrath, G. P. Eberli, B. Laurich, G. Desbois, R. J. Weger, and J. L. Urai, "Electrical and fluid flow properties of carbonate microporosity types from multiscale digital image analysis and mercury injection," AAPG Bulletin, vol. 99, no. 11, pp. 20772098, 2015.

[37] J. He, W. Ding, A. Li et al., "Quantitative microporosity evaluation using mercury injection and digital image analysis in tight carbonate rocks: A case study from the Ordovician in the Tazhong Palaeouplift, Tarim Basin, NW China," Journal of Natural Gas Science and Engineering, vol. 34, pp. 627-644, 2016.

[38] F. Wu, Q. Fan, D. Huang, L. Ma, X. Liang, and L. Sima, "Predicting gas-water relative permeability using Nuclear Magnetic Resonance and Mercury Injection Capillary Pressure measurements," Journal of Natural Gas Science and Engineering, vol. 32, pp. 35-47, 2016.

[39] H. H. Yuan and B. F. Swanson, "Resolving pore-space characteristics by rate-controlled porosimetry," SPE Formation Evaluation, vol. 4, no. 1, pp. 17-24, 1989.

[40] C. H. Arns, "A comparison of pore size distributions derived by NMR and X-ray-CT techniques," Physica A: Statistical Mechanics and its Applications, vol. 339, no. 1-2, pp. 159-165, 2004.

[41] V. Anand and G. J. Hirasaki, "Diffusional coupling between micro and macroporosity for NMR relaxation in sandstones and grainstones," Petrophysics, vol. 48, no. 4, pp. 289-307, 2007.

[42] H. Daigle and B. Dugan, "Extending NMR data for permeability estimation in fine-grained sediments," Marine and Petroleum Geology, vol. 26, no. 8, pp. 1419-1427, 2009.

[43] O. Talabi and M. J. Blunt, "Pore-scale network simulation of NMR response in two-phase flow," Journal of Petroleum Science and Engineering, vol. 72, no. 1-2, pp. 1-9, 2010.

[44] Z. Hossain, C. A. Grattoni, M. Solymar, and I. L. Fabricius, "Petrophysical properties of greensand as predicted from NMR measurements," Petroleum Geoscience, vol. 17, no. 2, pp. 111-125, 2011.

[45] W. Hübner, "Studying the pore space of cuttings by NMR and $\mu$ CT," Journal of Applied Geophysics, vol. 104, pp. 97-105, 2014.

[46] O. Faÿ-Gomord, J. Soete, K. Katika et al., "New insight into the microtexture of chalks from NMR analysis," Marine and Petroleum Geology, vol. 75, pp. 252-271, 2016.

[47] M. Wang, S. Zhang, F. Zhang et al., "Quantitative research on tight oil microscopic state of Chang 7 Member of Triassic Yanchang Formation in Ordos Basin, NW China," Petroleum Exploration and Development, vol. 42, no. 6, pp. 827-832, 2015.

[48] H. Zhu, D. Zhong, J. Yao et al., "Alkaline diagenesis and its effects on reservoir porosity: a case study of Upper Triassic 
Chang 7 Member tight sandstone in Ordos Basin, NW China," Petroleum Exploration and Development, vol. 42, no. 1, pp. 5665, 2015.

[49] C. Y. Liu, H. G. Zhao, J. F. Zhao, J. Q. Wang, D. D. Zhang, and M. H. Yang, "Temporo-spatial coordinates of evolution of the ordos basin and its mineralization responses," Acta Geologica Sinica-English Edition, vol. 82, pp. 1229-1243, 2008.

[50] Y. Wan, H. Xie, H. Yang et al., "Is the ordos block archean or paleoproterozoic in age? implications for the precambrian evolution of the north China craton," American Journal of Science, vol. 313, no. 7, pp. 683-711, 2013.

[51] J. J. Yang, Tectonic Evolution and Oil Gas Reservoirs Distribution in Ordos Basin, Petroleum Industry Press, Beijing, China, 2002.

[52] R. Y. Chen, X. R. Luo, Z. K. Chen, J. Yu, and Y. Yang, "Restoration of burial history of four periods in Ordos Basin," Acta Petrolei Sinica, vol. 27, pp. 43-47, 2006.

[53] Q. Xu, W. Shi, X. Xie et al., "Deep-lacustrine sandy debrites and turbidites in the lower Triassic Yanchang Formation, southeast Ordos Basin, central China: Facies distribution and reservoir quality," Marine and Petroleum Geology, vol. 77, pp. 1095-1107, 2016.

[54] X. Li, X. Liu, S. Zhou et al., "Hydrocarbon origin and reservoir forming model of the Lower Yanchang Formation, Ordos Basin," Petroleum Exploration and Development, vol. 39, no. 2, pp. 184-193, 2012.

[55] J. Yu, Y. J. Yang, and J. L. Du, "Sedimentation during the transgression period in Late Triassic Yanchang Formation, Ordos Basin," Petroleum Exploration and Development, vol. 37, pp. 181-187, 2010.

[56] Y. Guo, J. Liu, H. Yang et al., "Hydrocarbon accumulation mechanism of low permeable tight lithologic oil fields in the Yanchang Formation, Ordos Basin, China," Petroleum Exploration and Development, vol. 39, no. 4, pp. 447-456, 2012.

[57] X. Deng, W. Li, X. Liu, J. Pang, and X. Leu, "Discussion on the stratigraphic boundary between middle triassic and upper triassic," Acta Geologica Sinica, vol. 83, no. 8, pp. 1089-1096, 2009.

[58] H. Yuan, "Advances in APEX Technology," in SCA, 1990.

[59] J. M. Kate and C. S. Gokhale, "A simple method to estimate complete pore size distribution of rocks," Engineering Geology, vol. 84, no. 1-2, pp. 48-69, 2006.

[60] M. Schmitt, C. P. Fernandes, J. A. B. da Cunha Neto, F. G. Wolf, and V. S. S. dos Santos, "Characterization of pore systems in seal rocks using Nitrogen Gas Adsorption combined with Mercury Injection Capillary Pressure techniques," Marine and Petroleum Geology, vol. 39, no. 1, pp. 138-149, 2013.

[61] "Oilfield Curve measurement of rock capillary pressure with constant rate method," in Q/SY DQ1531-2012, 2012.

[62] J. Loren and J. Robinson, "Relations between pore size fluid and matrix properties, and NML measurements," Society of Petroleum Engineers Journal, vol. 10, no. 03, pp. 268-278, 2013.

[63] K. R. Brownstein and C. E. Tarr, "Importance of classical diffusion in NMR studies of water in biological cells," Physical Review A: Atomic, Molecular and Optical Physics, vol. 19, no. 6, pp. 2446-2453, 1979.

[64] K. Keating and R. Knight, "The effect of spatial variation in surface relaxivity on nuclear magnetic resonance relaxation rates," Geophysics, vol. 77, no. 5, pp. E365-E377, 2012.

[65] R. B. Robinson, "Classification of reservoir rocks by surface texture," AAPG Bulletin, vol. 50, pp. 547-559, 1966.
[66] J. H. M. Thomeer, "Introduction of a pore geometrical factor defined by a capillary pressure curve," Petroleum Transactions, AIME, Geoarabia Journal of the Middle East Petroleum Geosciences, vol. 219, pp. 354-358, 1960.

[67] B. F. Swanson, "A simple correlation between permeabilities and mercury capillary pressures," Journal of Petroleum Technology, vol. 33, no. 12, pp. 2498-2504, 1981.

[68] J. Wells and J. Amaefule, "Capillary Pressure and Permeability Relationships in Tight Gas Sands," in Proceedings of the SPE/DOE Low Permeability Gas Reservoirs Symposium, Denver, Colorado, USA, 1985.

[69] B. Guo, A. Ghalambor, and S. Duan, "Correlation between sandstone permeability and capillary pressure curves," Journal of Petroleum Science and Engineering, vol. 43, no. 3-4, pp. 239246, 2004.

[70] B. S. Kwon and G. R. Pickett, "A new proe structure model and pore structure interrelationships," in SPWLA 16Th Annual Logging Symposium, 1975.

[71] R. Aguilera, "Incorporating capillary pressure, pore throat aperture radii, height above free-water table, and Winland r35 values on Pickett plots," AAPG Bulletin, vol. 86, no. 4, pp. 605624, 2002.

[72] S. An, J. Yao, Y. Yang, L. Zhang, J. Zhao, and Y. Gao, "Influence of pore structure parameters on flow characteristics based on a digital rock and the pore network model," Journal of Natural Gas Science and Engineering, vol. 31, pp. 156-163, 2016.

[73] L. D. Gelb, K. E. Gubbins, R. Radhakrishnan, and M. SliwinskaBartkowiak, "Phase separation in confined systems," Reports on Progress in Physics, vol. 62, no. 12, pp. 1573-1659, 1999.

[74] F. Casanova, C. E. Chiang, C.-P. Li et al., "Effect of surface interactions on the hysteresis of capillary condensation in nanopores," EPL (Europhysics Letters), vol. 81, no. 2, pp. 226234, 2007.

[75] D. R. Cole, S. Ok, A. Striolo, and A. Phan, "Hydrocarbon behavior at nanoscale interfaces," Reviews in Mineralogy and Geochemistry, vol. 75, pp. 495-545, 2013.

[76] K. E. Gubbins, Y. Long, and M. Śliwinska-Bartkowiak, “Thermodynamics of confined nano-phases," The Journal of Chemical Thermodynamics, vol. 74, pp. 169-183, 2014. 

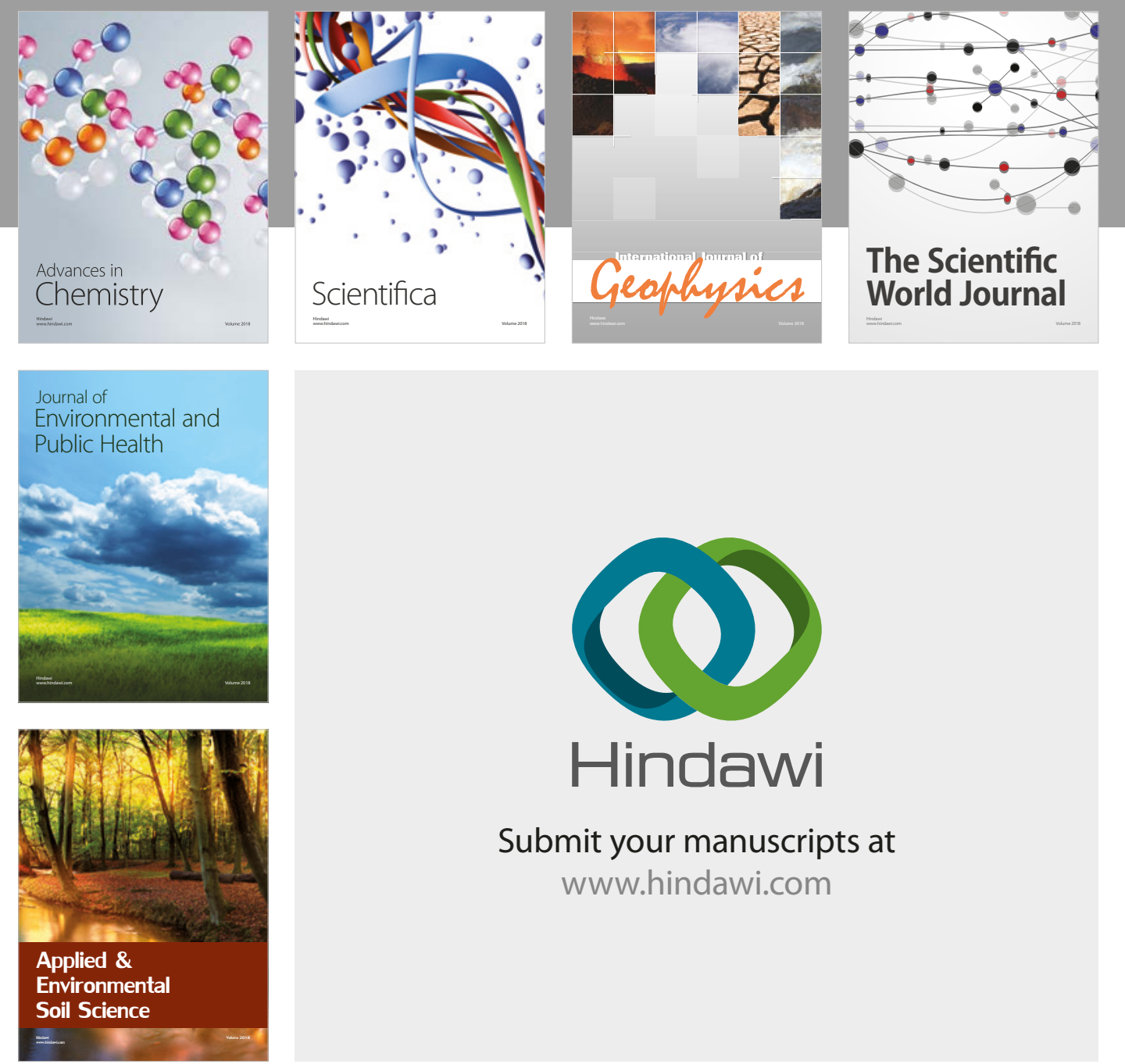

The Scientific

\section{World Journal}
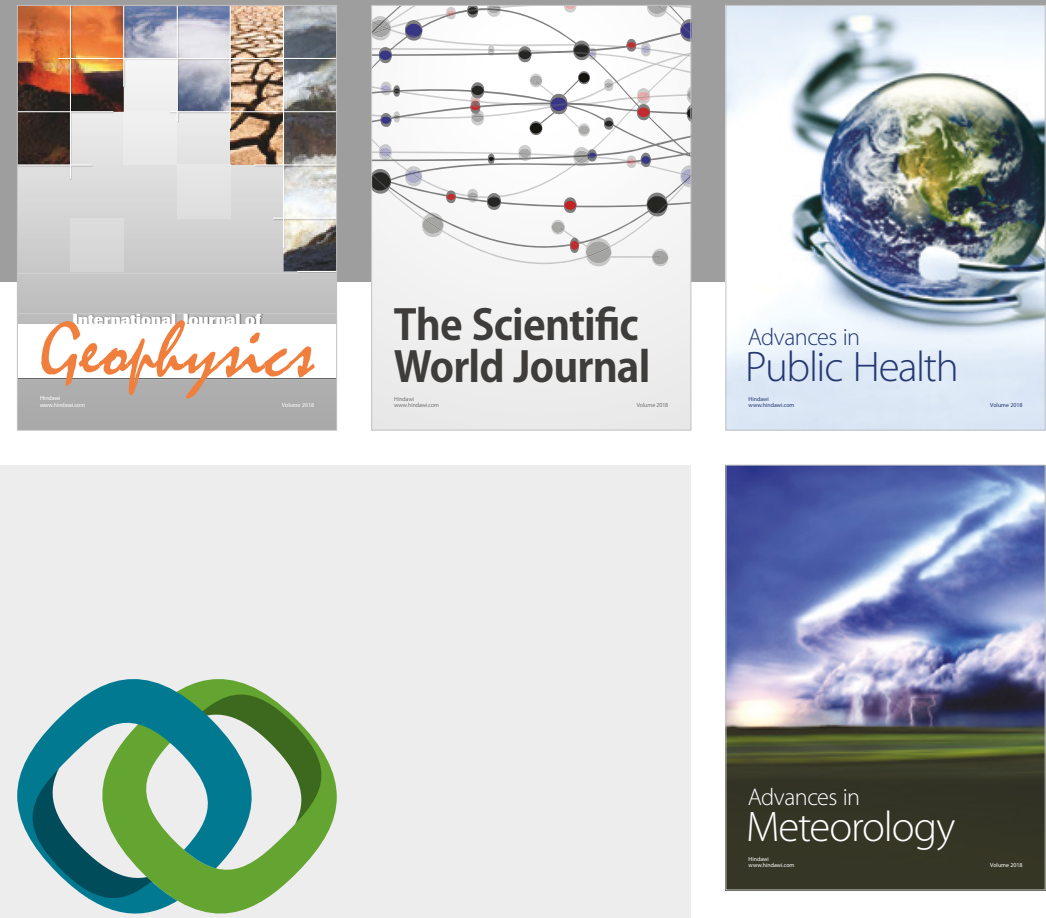

Advan

Public Health

\section{Hindawi}

Submit your manuscripts at

www.hindawi.com
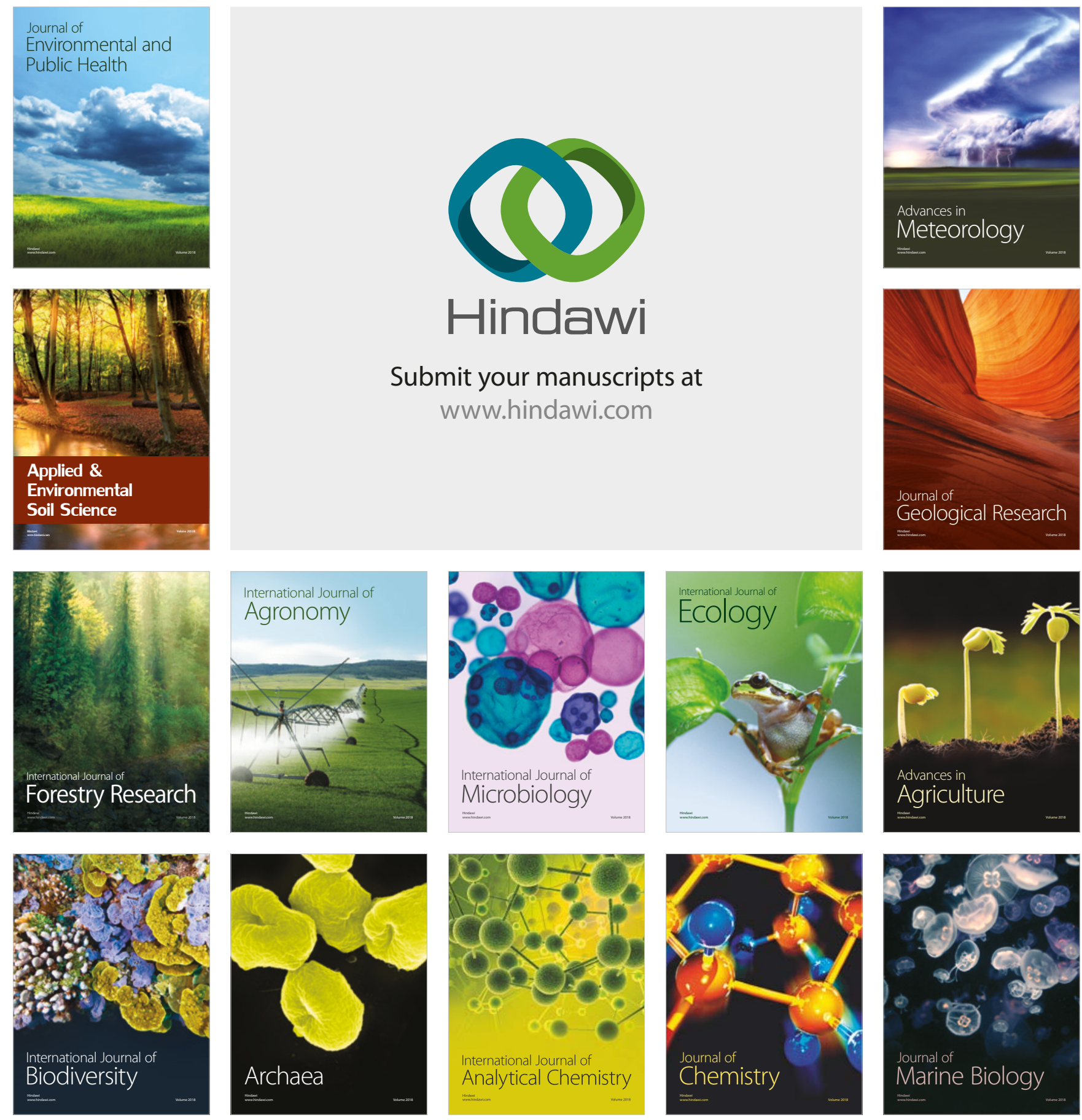